\begin{abstract}
DOES IDIOSYNCRATIC VOLATILITY PROXY FOR A MISSING RISK FACTOR? EVIDENCE FROM USING PORTFOLIOS AS TEST ASSETS
\end{abstract}

\author{
by David Gempesaw
}

We use various samples of portfolios (Fama-French portfolios formed on size and book-to-market, Fama-French industry portfolios, and exchange traded funds) as test assets to investigate whether the negative relation between lagged idiosyncratic volatility (IVOL) and future average returns initially documented by Ang, Hodrick, Xing, and Zhang (2006) is due to a missing risk factor. Analytically, we show that if IVOL proxies for a missing risk factor, then the negative relation between IVOL and returns persists at a portfolio level since systematic risk is not eliminated through diversification. However, when we take it to the data, we do not find economically and statistically significant evidence of a relation between lagged IVOL and subsequent average returns. Taken together, our results suggest that the IVOL puzzle is not due to a missing risk factor. 


\title{
DOES IDIOSYNCRATIC VOLATILITY PROXY \\ FOR A MISSING RISK FACTOR? \\ EVIDENCE FROM USING PORTFOLIOS AS TEST ASSETS
}

\author{
A Thesis \\ Submitted to the \\ Faculty of Miami University \\ in partial fulfillment of \\ the requirements for the degree of \\ Master of Arts \\ Department of Economics \\ by \\ David Gempesaw \\ Miami University \\ Oxford, Ohio \\ 2014
}

Advisor:

Dr. Haimanot Kassa

Reader:

Dr. Tyler Henry

Reader:

Dr. George Davis 


\section{Contents}

List of Tables

1 Introduction $\quad 1$

2 Idiosyncratic Volatility as a Proxy for Risk Exposure 5

3 Data and Variable Definitions $\quad 9$

3.1 Measuring Idiosyncratic Volatility . . . . . . . . . . . . . . . . . . . . 9

3.2 Fama-French 100 and 25 Portfolios Formed on Size and B/M . . . . . . . . . 10

3.3 Fama-French 49 Industry Portfolios . . . . . . . . . . . . . . . . . . 11

3.4 CRSP - NYSE/AMEX/NASDAQ Stocks . . . . . . . . . . . . . . 11

3.5 CRSP - Exchange Traded Funds . . . . . . . . . . . . . . . . . . . . . . . 11

4 Empirical Results $\quad 12$

4.1 Descriptive Statistics and Correlation Matrix . . . . . . . . . . . . . . . . . . 12

4.2 Quintile Portfolio Sorting on Idiosyncratic Volatility . . . . . . . . . . . . . 13

4.3 Fama-MacBeth Cross-sectional Regressions . . . . . . . . . . . . . . . 16

4.4 Robustness Checks . . . . . . . . . . . . . . . . . . . . . . . 17

5 Conclusion $\quad 19$

$\begin{array}{lr}\text { References } & 21\end{array}$

$\begin{array}{ll}\text { Tables } & 24\end{array}$

$\begin{array}{ll}\text { Appendix } & 31\end{array}$ 


\section{List of Tables}

1 Descriptive Statistics . . . . . . . . . . . . . . . . . 24

2 Correlation Matrix . . . . . . . . . . . . . . . . . . 25

3 Sorting of Individual Stocks (Replication of Results from Ang et al. (2006)) . 26

4 Sorting of 100 Portfolios Formed on Size and B/M . . . . . . . . . . . . 27

5 Sorting of 25 Portfolios Formed on Size and B/M . . . . . . . . . . . . . 28

6 Fama-MacBeth Regressions: 100 Portfolios Formed on Size and B/M . . . . 29

7 Fama-MacBeth Regressions: 25 Portfolios Formed on Size and B/M . . . . . 30

A8 Sorting of 49 Industry Portfolios . . . . . . . . . . . . . . . . . . . 31

A9 Fama-MacBeth Regressions: 49 Industry Portfolios . . . . . . . . . . . . . . 32

A10 Sorting of Exchange Traded Funds . . . . . . . . . . . . . . . . . . 33

A11 Fama-MacBeth Regressions: Exchange Traded Funds . . . . . . . . . . . . . 34

A12 Sorting of 100 Portfolios Formed on Size and B/M (Equal Weighted Returns) 35

A13 Sorting of 25 Portfolios Formed on Size and B/M (Equal Weighted Returns) 36

A14 Sorting of 49 Industry Portfolios (Equal Weighted Returns) . . . . . . . . . . 37

A15 Fama-MacBeth Regressions: 100 Portfolios Formed on Size and B/M (Equal Weighted Returns

A16 Fama-MacBeth Regressions: 25 Portfolios Formed on Size and B/M (Equal Weighted Returns) . . . . . . . . . . . . . . . . . 39

A17 Fama-MacBeth Regressions: 49 Industry Portfolios (Equal Weighted Returns) 40 


\section{Acknowledgments}

I would like to thank Dr. Haim Kassa, my thesis advisor, for his invaluable guidance and words of advice throughout the course of my research. I also thank Dr. George Davis and Dr. Tyler Henry for serving as members of my thesis committee. I am grateful to all of my professors and the Department of Economics for providing me with a strong foundation as I begin my doctoral studies. I appreciate the friendship and assistance of my classmates who worked alongside me for the past year. Finally, I must express my profound gratitude to my family for their constant encouragement and support. 


\section{Introduction}

The capital asset pricing model (CAPM) developed by Sharpe (1964), Lintner (1965), and Black (1972) predicts that only systematic risk is priced in equilibrium; idiosyncratic risk should not explain any of the cross-sectional variation in expected returns as it can be theoretically eliminated through diversification. While the CAPM has remained the centerpiece of asset pricing theory since its introduction, it has performed poorly in empirical applications due in part to the restrictive assumptions of the model regarding investor behavior and market structure. Research has shown that other variables have explanatory power for returns beyond a security's market beta. Several authors have explored idiosyncratic return volatility (IVOL) and its relation to expected returns to determine whether idiosyncratic risk may be priced. If investors do not hold a well diversified portfolio (whether it be due to constraints or preferences), then idiosyncratic risk may play a role in equilibrium. ${ }^{1}$

Certain variations of the CAPM predict a positive relation between idiosyncratic volatility and expected returns. Levy (1978) develops a modified version of the CAPM to demonstrate that when investors hold undiversified portfolios, idiosyncratic risk has an impact on equilibrium prices and investors demand additional compensation for exposure to higher idiosyncratic risk. Merton (1987) extends the CAPM to allow for incomplete information, assuming that investors will only use those securities about which they are informed when creating their optimal portfolios. When this assumption of complete information is relaxed, the expected return of a security will include a "shadow cost" as compensation for incomplete information. This "shadow cost" is proportional to the idiosyncratic volatility of the security. Therefore, in equilibrium, expected returns will be positively related to idiosyncratic risk. More recently, Malkiel and Xu (2006) develop a model with "constrained" investors who are unable to hold the market portfolio for various reasons, such as transactions costs, incomplete information, taxes, or short sale restrictions. In their model, expected returns will include an extra risk premium for the undiversified idiosyncratic risk imposed by the investment constraints. The authors also show empirically that idiosyncratic volatility is positively correlated with expected stock returns. All of the aforementioned models predict that idiosyncratic volatility is positively correlated to returns.

However, recent research has been inconsistent with these predictions. Presenting initial

\footnotetext{
${ }^{1}$ Part of the empirical literature in this area has focused on the time-series relation between average stock risk and the stock market return, e.g., Goyal and Santa-Clara (2003), Wei and Zhang (2005), Bali et al. (2005), and Guo and Savickas $(2006,2008)$. This paper focuses on the cross-sectional relation between idiosyncratic risk and stock returns.
} 
evidence of what has since been coined "the idiosyncratic volatility puzzle," Ang, Hodrick, Xing, and Zhang (2006) (AHXZ) document a negative relation between idiosyncratic volatility and subsequent returns of US stocks. The authors measure idiosyncratic volatility relative to the Fama and French (1993) three factor model (FF3). Their findings are robust after testing over different sample periods and controlling for firm characteristics such as size, value, momentum, liquidity, trading volume, and dispersion of analyst forecasts. Ang et al. (2009) build upon these findings using a broad sample of international developed markets to provide further support of their prior conclusions. The authors are able to rule out other possible explanatory factors including market frictions, higher moments of returns, and asymmetric information. ${ }^{2}$

Various authors have since presented explanations for the findings of AHXZ. Hou and Loh (2014) provide a comprehensive evaluation of a majority of the existing explanations related to firm-specific characteristics and group them into three categories. The first category includes explanations based on investor preferences for lottery-like payoffs which suggest that idiosyncratic volatility may be related to an attribute that proxies for the lottery feature of a stock. $^{3}$ The second category of papers identify various types of market frictions as potential explanations. ${ }^{4}$ The remaining group of explanations includes any others which do not relate to the first two categories, such as fundamental uncertainty or earnings surprises. ${ }^{5}$ Hou and Loh (2014) find that many of the explanatory variables individually explain less than $10 \%$ of the puzzle, while explanations based on lottery preferences, short-term return reversal, and earnings surprises together can account for $60-85 \%$ of the negative relation. They ultimately conclude that a significant portion of the idiosyncratic volatility puzzle remains unexplained.

An alternative explanation is that the IVOL puzzle results from estimated idiosyncratic volatility acting as a proxy for a missing systematic risk factor. If an asset pricing model omits a risk factor, then the measured idiosyncratic return volatility would partially reflect exposure to the omitted risk factor and, therefore, would be associated with a risk premium. Assets with higher exposure to the omitted risk factor will appear to have higher idiosyncratic volatility. As AHXZ find that the alphas of high idiosyncratic volatility stocks are negative,

\footnotetext{
${ }^{2}$ Other recent studies documenting a negative relation include Jiang et al. (2009) and Barberis and Huang (2008). A recent study documenting no relation is Bali and Cakici (2008).

${ }^{3}$ E.g., skewness (Barberis and Huang (2008)), coskewness (Chabi-Yo and Yang (2010)), expected idiosyncratic skewness (Boyer et al. (2010)), maximum daily return (Bali et al. (2011)), and retail trading proportion (Han and Kumar (2013)).

${ }^{4}$ E.g., one-month return reversal (Fu (2009) and Huang et al. (2009)), illiquidity (Bali and Cakici (2008)), and short-sale constraints (Boehme et al. (2009)).

${ }^{5}$ E.g., fundamental uncertainty (Johnson (2004)) and earnings surprises (Jiang et al. (2009) and Wong (2011)).
} 
this indicates that the model overestimates expected returns of stocks with high idiosyncratic volatility. The product of the pricing of the missing factor and the stock's exposure to this factor would result in the observed mispricing.

AHXZ consider this possibility and introduce the volatility of the market return as a new cross-sectional factor. However, they find that exposure to aggregate market variance accounts for very little of the low average returns of high idiosyncratic volatility stocks. Chen and Petkova (2014) decompose market variance into two components: average stock variance and average stock correlation. They propose average stock variance as the missing risk factor. The authors find that the price of risk for average stock variance is negative, while stocks with higher idiosyncratic volatility have positive exposures to innovations in average stock variance. These two effects combine to produce the observed IVOL puzzle. Duarte et al. (2014) also argue that the IVOL puzzle is due to unaccounted systematic risk. The authors identify common components of idiosyncratic volatility measured in relation to the FF3 model. By decomposing idiosyncratic volatility into predicted (by the common component(s)) and residual idiosyncratic volatility, they show that almost all of the mispricing documented by AHXZ can be explained by predicted idiosyncratic volatility. The authors proxy for the missing risk factor using the return difference between stocks with high and low predicted idiosyncratic volatility and find that this factor has significant explanatory power for the cross-section of returns. ${ }^{6}$

In this paper, we argue that if the apparent negative relation between lagged idiosyncratic volatility and future average return is in fact due to a missing risk factor, then the negative relation should persist for portfolios of stocks as the exposure of individual stocks to the risk factor will still exist within a portfolio. Since idiosyncratic risk sources are theoretically independent, portfolio diversification can reduce firm-specific risk to negligible levels. However, common sources of risk that affect all firms will not be eliminated through diversification. Because of this, we propose the use of portfolios to test this particular explanation of the IVOL puzzle since portfolio returns will asymptotically be solely reflective of exposure to systematic risk.

If we find a significant relation between idiosyncratic volatility and return for portfolios, we would not necessarily be able to distinguish whether the result was due to exposure to a missing risk factor or due to "true" idiosyncratic risk being priced, since any portfolio other than the market portfolio will still carry some level of idiosyncratic risk. Therefore, this

\footnotetext{
${ }^{6}$ Herskovic et al. (2014) document that exposure to the common factor in idiosyncratic volatility is a priced cross-sectional risk factor, but their findings do not resolve the IVOL puzzle.
} 
approach cannot be used to confirm the existence of a missing risk factor. Furthermore, if either a missing risk factor or "true" idiosyncratic risk were priced, it would increase the likelihood of finding a statistically significant result when using portfolios as test assets. However, if we do not find a significant relation between idiosyncratic volatility and return for portfolios, then this would provide conclusive evidence that a missing risk factor is not the source of the IVOL puzzle.

Following AHXZ, we use within-month daily data to measure idiosyncratic volatility based on the FF3 model. We first confirm the result of AHXZ by sorting NYSE, AMEX, and NASDAQ stocks from July 1963 to December 2000 into value-weighted quintile portfolios ranked on idiosyncratic volatility. We create a portfolio representing the return difference between the highest and lowest idiosyncratic volatility stocks to examine the effect of idiosyncratic volatility on returns. For this portfolio, AHXZ report a monthly raw return of $-1.06 \%$ and FF3 alpha of $-1.31 \%$ (t-statistic of -3.10 and -7.00 , respectively). Similarly, we find a monthly raw return of $-1.059 \%$ and FF3 alpha of $-1.356 \%$ (t-statistic of -3.12 and -7.22, respectively), representing an economically and statistically significant return differential. We then repeat this sorting analysis over the same time period using samples of 100 and 25 portfolios formed on size and book-to-market ratio and do not find a robustly significant relation. Specifically, when sorting 100 portfolios based on idiosyncratic volatility, the FF3 risk-adjusted return differential between the highest and lowest idiosyncratic volatility portfolios is $-0.156 \%$ with a t-statistic of -1.30 . When sorting 25 portfolios based on idiosyncratic volatility, the FF3 alpha is $0.036 \%$ with a t-statistic of 0.29 . The magnitude and statistical significance of the risk-adjusted return differential decreases monotonically with the level of portfolio diversification, reflecting the diminishing idiosyncratic risk within the portfolio. We also estimate the pricing of idiosyncratic volatility for portfolios using Fama and MacBeth (1973) regressions and fail to find evidence that idiosyncratic volatility has predictive power for returns. After controlling for various portfolio characteristics and exposures to risk factors, we find a coefficient on lagged idiosyncratic volatility of -0.102 and -0.128 (expressed in percentage points) for the 100 and 25 portfolios, respectively. Both coefficient estimates are not statistically significant.

Overall, we do not find empirical evidence of a relation between lagged idiosyncratic volatility and average returns using portfolios as test assets. The results are qualitatively unchanged when using data over a wider time period, alternative portfolio samples, and different weighting schemes to compute portfolio returns. This evidence points to the conclusion that the observed IVOL puzzle is not due to a missing risk factor. 
The rest of this paper is organized as follows. Section 2 outlines the theoretical motivation for using portfolios as test assets to investigate whether idiosyncratic volatility proxies for a missing risk factor. Section 3 defines the methodology used to measure idiosyncratic volatility and describes the data used in the analysis. Section 4 presents our empirical findings regarding the relation between idiosyncratic volatility and the cross-section of expected returns using portfolios as test assets. Section 5 concludes.

\section{Idiosyncratic Volatility as a Proxy for Risk Exposure}

Researchers often use the standard Fama and French (1993) three factor linear regression model to decompose the excess return $r$ on asset $i$ at any given time $t$ into a systematic and idiosyncratic component:

$$
r_{i t}=\alpha_{i}+\beta_{i}^{M K T} M K T_{t}+\beta_{i}^{S M B} S M B_{t}+\beta_{i}^{H M L} H M L_{t}+e_{i t}
$$

where $M K T$ is the excess market return, $S M B$ is the size premium (excess returns of small stocks over big stocks), $H M L$ is the book-to-market premium (excess returns of value stocks over growth stocks), and $\alpha_{i}$ is the mispricing of asset $i .^{7}$ If this model is an exact specification, then $\alpha_{i}$ is equal to zero. However, if this specification has a missing risk factor, then the intercept is not zero, and it is correlated with the variance of $e_{i}{ }^{8}$

Assume that the exact asset pricing specification with the additional risk factor $F$ is given by

$$
r_{i}=\beta_{i}^{M K T} M K T+\beta_{i}^{S M B} S M B+\beta_{i}^{H M L} H M L+\gamma_{i} F+\epsilon_{i}
$$

where $\gamma_{i}$ is the loading of security $i$ on the missing factor $F$ and $\epsilon_{i}$ is the "true" idiosyncratic return. Under the assumption of an exact asset pricing specification, the intercept in equation (2) disappears. From equations (1) and (2), the residual from (1) can be shown to be a linear combination of the missing factor and the true idiosyncratic return: ${ }^{9}$

$$
e_{i}=\gamma_{i} F+\epsilon_{i}
$$

\footnotetext{
${ }^{7}$ For ease of notation, the time subscript $t$ is subsequently omitted.

${ }^{8}$ The relation between the mispricing and the variance of the residuals can be shown using the optimal orthogonal portfolio developed by MacKinlay (1995). It is optimal because it can be combined with the other factor portfolios to form the tangency portfolio. It is also orthogonal to the other factor portfolios which leaves the coefficients on the other factors unchanged.

${ }^{9}$ Equation (3) is only true if econometricians force the intercept in (1) to zero.
} 
and the variance of the residual from (1) is

$$
\operatorname{Var}\left(e_{i}\right)=\gamma_{i}^{2} \operatorname{Var}(F)+\operatorname{Var}\left(\epsilon_{i}\right) .
$$

Equation (4) implies that the measure of idiosyncratic volatility from a misspecified model depends on the squared loading on the missing factor $\gamma_{i}^{2}$ as well as the asset's "true" idiosyncratic volatility $\operatorname{Var}\left(\epsilon_{i}\right)$. Therefore, using the idiosyncratic volatility $\operatorname{Var}\left(e_{i}\right)$ in a pricing equation captures the effects of the asset's exposure to the missing factor. We can test this conjecture by using portfolios as test assets. As long as asset returns are not perfectly positively correlated, combining individual assets into a portfolio will reduce idiosyncratic risk, but systematic risk will not be eliminated. If the pricing implication of idiosyncratic volatility is indeed due to a missing factor, then we should find a similar result when we examine the idiosyncratic volatility of a portfolio's returns.

The return of a given portfolio $p$ with $n$ assets each with a weight of $w_{i}$ is

$$
r_{p}=\sum_{i=1}^{n} w_{i} r_{i}
$$

and the variance of the portfolio's returns is

$$
\operatorname{Var}\left(r_{p}\right)=\sum_{i=1}^{n} w_{i}^{2} \operatorname{Var}\left(r_{i}\right)+\sum_{i=1}^{n} \sum_{\substack{j=1 \\ i \neq j}}^{n} w_{i} w_{j} \operatorname{Cov}\left(r_{i}, r_{j}\right)
$$

Similarly, the variance of the residuals after regressing the portfolio return on the FF3 factors in (1) is

$$
\operatorname{Var}\left(e_{p}\right)=\sum_{i=1}^{n} w_{i}^{2} \operatorname{Var}\left(e_{i}\right)+\sum_{i=1}^{n} \sum_{\substack{j=1 \\ i \neq j}}^{n} w_{i} w_{j} \operatorname{Cov}\left(e_{i}, e_{j}\right) .
$$

Using equations (3) and (4) gives

$$
\operatorname{Var}\left(e_{p}\right)=\sum_{i=1}^{n} w_{i}^{2}\left[\gamma_{i}^{2} \operatorname{Var}(F)+\operatorname{Var}\left(\epsilon_{i}\right)\right]+\sum_{i=1}^{n} \sum_{\substack{j=1 \\ i \neq j}}^{n} w_{i} w_{j} \operatorname{Cov}\left(\gamma_{i} F+\epsilon_{i}, \gamma_{j} F+\epsilon_{j}\right)
$$




$$
\begin{aligned}
\operatorname{Var}\left(e_{p}\right) & =\sum_{i=1}^{n} w_{i}^{2}\left[\gamma_{i}^{2} \operatorname{Var}(F)+\operatorname{Var}\left(\epsilon_{i}\right)\right] \\
& +\sum_{i=1}^{n} \sum_{\substack{j=1 \\
i \neq j}}^{n} w_{i} w_{j}\left[\operatorname{Cov}\left(\gamma_{i} F, \gamma_{j} F\right)+\operatorname{Cov}\left(\gamma_{i} F, \epsilon_{j}\right)+\operatorname{Cov}\left(\epsilon_{i}, \gamma_{j} F\right)+\operatorname{Cov}\left(\epsilon_{i}, \epsilon_{j}\right)\right] .
\end{aligned}
$$

By construction, the residual $\epsilon$ is orthogonal to $F$. With the assumption that the residuals are independent and identically distributed, ${ }^{10}$ the second term in brackets reduces down to the variance due to the missing risk factor.

$$
\operatorname{Var}\left(e_{p}\right)=\sum_{i=1}^{n} w_{i}^{2}\left[\gamma_{i}^{2} \operatorname{Var}(F)+\operatorname{Var}\left(\epsilon_{i}\right)\right]+\sum_{i=1}^{n} \sum_{\substack{j=1 \\ i \neq j}}^{n} w_{i} w_{j} \gamma_{i} \gamma_{j} \operatorname{Var}(F)
$$

Rearranging (10) gives

$$
\operatorname{Var}\left(e_{p}\right)=\left[\sum_{i=1}^{n} w_{i}^{2} \gamma_{i}^{2}+\sum_{i=1}^{n} \sum_{\substack{j=1 \\ i \neq j}}^{n} w_{i} w_{j} \gamma_{i} \gamma_{j}\right] \operatorname{Var}(F)+\sum_{i=1}^{n} w_{i}^{2} \operatorname{Var}\left(\epsilon_{i}\right)
$$

We also have the following expression for the portfolio, similar to (4) describing the residual variance of an asset:

$$
\operatorname{Var}\left(e_{p}\right)=\gamma_{p}^{2} \operatorname{Var}(F)+\operatorname{Var}\left(\epsilon_{p}\right)
$$

From (11) and (12), we conclude the following:

$$
\begin{gathered}
\gamma_{p}^{2} \operatorname{Var}(F)=\left[\sum_{i=1}^{n} w_{i}^{2} \gamma_{i}^{2}+\sum_{i=1}^{n} \sum_{\substack{j=1 \\
i \neq j}}^{n} w_{i} w_{j} \gamma_{i} \gamma_{j}\right] \operatorname{Var}(F) \\
\operatorname{Var}\left(\epsilon_{p}\right)=\sum_{i=1}^{n} w_{i}^{2} \operatorname{Var}\left(\epsilon_{i}\right) .
\end{gathered}
$$

In order to see how the "true" idiosyncratic variance of the portfolio $\operatorname{Var}\left(\epsilon_{p}\right)$ diminishes as more stocks are added into the portfolio, consider an equally weighted portfolio where

\footnotetext{
${ }^{10}$ We expect a higher degree of correlation among stocks within the Fama-French 49 industry portfolios compared to the Fama-French portfolios formed on size and book-to-market. Consistent with our expectations, we observe higher residual variance for the 49 industry portfolios than the 100 portfolios formed on size and book-to-market.
} 
$w_{i}=\frac{1}{n}$ for all $i$.

$$
\begin{aligned}
\operatorname{Var}\left(\epsilon_{p}\right) & =\sum_{i=1}^{n}\left(\frac{1}{n}\right)^{2} \operatorname{Var}\left(\epsilon_{i}\right) \\
& =\frac{1}{n}\left[\sum_{i=1}^{n} \frac{\operatorname{Var}\left(\epsilon_{i}\right)}{n}\right]
\end{aligned}
$$

The term within the brackets is the average idiosyncratic variance of the stocks in the portfolio, which converges to the population average idiosyncratic variance as $n$ increases. However, the additional $n$ in the denominator outside of the brackets will cause the idiosyncratic variance of the portfolio to go to zero in the limit.

Now consider the portion of the portfolio variance that is due to exposure to a missing factor, using the same assumption of an equally weighted portfolio.

$$
\gamma_{p}^{2} \operatorname{Var}(F)=\sum_{i=1}^{n}\left(\frac{1}{n}\right)^{2} \gamma_{i}^{2} \operatorname{Var}(F)+\sum_{i=1}^{n} \sum_{\substack{j=1 \\ i \neq j}}^{n}\left(\frac{1}{n}\right)^{2} \gamma_{i} \gamma_{j} \operatorname{Var}(F)
$$

Note that the first term represents $n$ terms and the second term represents $n(n-1)$ terms. If we define the average portion of $\gamma_{p}^{2} \operatorname{Var}(F)$ that results from the variances of individual stocks as

$$
\overline{\operatorname{Var}}=\frac{1}{n} \sum_{i=1}^{n} \gamma_{i}^{2} \operatorname{Var}(F)
$$

and the average portion of $\gamma_{p}^{2} \operatorname{Var}(F)$ that results from the covariances of stocks as

$$
\overline{C o v}=\frac{1}{n(n-1)} \sum_{i=1}^{n} \sum_{\substack{j=1 \\ i \neq j}}^{n} \gamma_{i} \gamma_{j} \operatorname{Var}(F)
$$

we can express (16) as

$$
\gamma_{p}^{2} \operatorname{Var}(F)=\frac{1}{n} \overline{\operatorname{Var}}+\frac{n-1}{n} \overline{\operatorname{Cov}} .
$$

As $n$ increases, the weight on $\overline{V a r}$ approaches zero and the weight on $\overline{C o v}$ approaches one. Therefore, $\gamma_{p}^{2} \operatorname{Var}(F)$ is not asymptotically eliminated as more stocks are added to the portfolio. $^{11}$

\footnotetext{
${ }^{11}$ In the extreme case, $\overline{C o v}$ may equal zero. For example, in an equally weighted portfolio, if half of the assets have a positive exposure and the other half of the assets have a negative exposure but in equal magnitude, then the exposure to the missing risk factor would cancel out. Given that we are dealing with
} 
In other words, if idiosyncratic volatility does proxy for a missing risk factor, then the negative relation between idiosyncratic volatility (as estimated in relation to a model omitting the risk factor) and expected return should persist when using portfolios as test assets. The exposure to the missing risk factor will still exist in the portfolio, while the "true" idiosyncratic volatility of the portfolio will disappear as the number of stocks increases and the portfolio approaches the market portfolio.

\section{Data and Variable Definitions}

In this section, we describe the methodology used to measure idiosyncratic volatility (Section 3.1) and outline the data and variables used in our analysis (Sections 3.2 through $3.5)$.

\subsection{Measuring Idiosyncratic Volatility}

To estimate the idiosyncratic volatility of returns, we follow the methodology of AHXZ. For each month and for each asset, we perform a time-series regression of daily returns in excess of the risk-free rate onto the daily returns of the factors in the FF3 model:

$$
r_{i t}=\alpha_{i}+\beta_{i}^{M K T} M K T_{t}+\beta_{i}^{S M B} S M B_{t}+\beta_{i}^{H M L} H M L_{t}+e_{i t}
$$

The residuals from these regressions represent idiosyncratic returns. Idiosyncratic volatility is defined as the standard deviation of the residuals from (20) and is calculated for each month. In all cases, we restrict the sample to months with at least 15 daily return observations. Data on the Fama-French factors and the monthly risk-free rate (one-month Treasury bill rate)

a systematic risk factor, we might assume that for a majority of stocks, the exposure to the factor is the same sign. Furthermore, since we believe that estimated idiosyncratic volatility is proxying for exposure to the factor, then stocks with higher idiosyncratic volatility should have stronger exposure to the factor. We can confirm this by looking at the results in Table 3. In Panel A, the alphas for portfolios 1 through 3 are slightly positive but close to zero and not strongly significant. In comparison, the alphas for portfolios 4 and 5 are negative, larger in magnitude, and much more statistically significant. In Panel B, the alphas for portfolio 1 are positive and significant, but small. However, portfolios 2 through 5 have negative alphas which increase in magnitude and significance with idiosyncratic volatility. Therefore, it is not likely that exposure to the factor will net to zero within a portfolio, as the exposure leading to negative alphas is more common among stocks, stronger in magnitude, and more significant than the exposure leading to positive alphas. With respect to the Fama-French portfolios, we recognize that since value weighted portfolio returns place less weight on smaller stocks and size is negatively related to idiosyncratic volatility, stocks with higher idiosyncratic volatility may receive lower weights in generating portfolio returns. Nevertheless, our results are robust to the use of equal weighted portfolio returns. 
are available through Wharton Research Data Services (WRDS).

\subsection{Fama-French 100 and 25 Portfolios Formed on Size and B/M}

Our primary analysis utilizes data for 100 portfolios and 25 portfolios of stocks formed on size (market equity) and book equity to market equity (B/M). We obtain the data sets from Kenneth French's website. ${ }^{12}$ The portfolios are formed using common stocks (share code 10 or 11) of all CRSP firms incorporated in the US and listed on the NYSE, AMEX, or NASDAQ (exchange code 1, 2, or 3) at the beginning of month $t$ with good shares, price, and return data for month $t$. Stocks are sorted into portfolios based on NYSE size and book-to-market breakpoints each month from July 1926 to December 2013. ${ }^{13}$ After filtering for available data for all variables in our analysis, the full sample period for this data is November 1926 to June 2013.

We use value weighted portfolio daily and monthly returns so that a firm's influence on the determination of the portfolio return is proportional to its size. ${ }^{14}$ The following variables are used as controls in Fama-MacBeth regressions. We control for size and book-to-market ratio using the natural log of average firm size in the portfolio $(\ln (\mathrm{SIZE}))$ and the natural $\log$ of the value weighted book-to-market ratio of the portfolio $(\ln (\mathrm{B} / \mathrm{M})) .{ }^{15}$ We control for return reversal and momentum using the lagged return (Return(-1)) and the six month compound return from month $t-7$ to $t-2$ (Return $(-7,-2))$. We also control for the portfolio's exposure to the market, size, book-to-market, and momentum risk factors of the Carhart (1997) four factor model (FF4):

$$
r_{i t}=\alpha_{i}+\beta_{i}^{M K T} M K T_{t}+\beta_{i}^{S M B} S M B_{t}+\beta_{i}^{H M L} H M L_{t}+\beta_{i}^{U M D} U M D_{t}+e_{i t}
$$

where $r_{i t}$ is the daily excess return of portfolio $i$. The coefficients $\beta_{M K T}, \beta_{S M B}, \beta_{H M L}$, and $\beta_{U M D}$ are estimated for each portfolio at a monthly frequency using daily data (with at least 15 daily return observations in a month).

\footnotetext{
${ }^{12} \mathrm{http}: / /$ mba.tuck.dartmouth.edu/pages/faculty/ken.french/data_library.html

${ }^{13}$ The use of NYSE breakpoints ensures that each portfolio contains an equal number of NYSE stocks. Since AMEX and NASDAQ stocks are smaller on average, this prevents the formation of size portfolios from becoming exchange specific and also provides more consistency and comparability over time.

${ }^{14}$ The Fama-French portfolio data sets also include equal weighted portfolio returns. We consider this data in our robustness checks.

${ }^{15}$ Book-to-market ratios are provided on an annual basis; we convert to a monthly frequency using linear interpolation. In the analyses using equal weighted portfolio returns, we use the natural log of the ratio of the sum of book equity to the sum of market equity.
} 


\subsection{Fama-French 49 Industry Portfolios}

We use the Fama-French 49 industry portfolios data set which sorts the same population of NYSE, AMEX, and NASDAQ stocks into 49 portfolios based on each stock's Standard Industrial Classification (SIC) code. We utilize the same variables from this data set as those outlined in Section 3.2 for the portfolios formed on size and book-to-market. The final sample period is November 1926 to June 2013.

\subsection{CRSP - NYSE/AMEX/NASDAQ Stocks}

We use daily and monthly stock returns from the Center for Research in Security Prices (CRSP) for common stocks (share code 10 or 11) listed on the NYSE, AMEX, or NASDAQ (exchange code 1, 2, or 3) with non-missing values for price, shares outstanding, and return for month $t .{ }^{16}$ We require at least 15 daily return observations for a stock to be included in the sample in a given month. We use CRSP share price (prc) and shares outstanding (shrout) to compute monthly market capitalization for each stock. For comparability to the Fama-French portfolios, we obtain stock data from CRSP for November 1926 to June 2013.

\subsection{CRSP - Exchange Traded Funds}

We use daily and monthly return data for exchange traded funds (ETFs) from the CRSP database, filtering using share code 73 which identifies shares of exchange-traded funds. The available daily return data begins in January 1993 with the S\&P 500 Depository Receipt and ends in December 2013 with data on 1,282 ETFs (1,599 uniquely identified ETFs over the entire time period). We require at least 15 daily return observations for an ETF to be included in our sample in a given month. Additionally, we require return data for at least 50 ETFs per month so that we have a sufficiently large representative sample. We use CRSP share price ( $p r c)$ and shares outstanding (shrout) to compute monthly market capitalization for each fund. For Fama-MacBeth regressions, we control for lagged returns, the six month compound return from month $t-7$ to $t-2$, the natural log of market capitalization, and the monthly factor loadings for the Carhart (1997) model. The final sample period is August 2000 to December 2013. We present results from our analysis of the full sample of ETFs ("All ETFs on CRSP") after the aforementioned filters. This sample includes leveraged ETFs, short ETFs, and ETFs investing in foreign, non-equity, or derivative securities. To ensure

\footnotetext{
${ }^{16}$ In general, we expect our sample of individual stocks to be similar to the sample of stocks being sorted into the Fama-French portfolios. This strengthens the validity of comparisons between the two.
} 
our results are relevant to the context of the original IVOL puzzle, we also present results for a further refined sample consisting of 560 ETFs primarily investing in long positions in US domestic equities ("US Domestic Equity ETFs"). ${ }^{17}$

\section{Empirical Results}

In this section, we present empirical results illustrating that the IVOL puzzle does not persist for portfolios. First, in Section 4.1, we report descriptive statistics and cross-sectional correlations for the variables of the Fama-French portfolios formed on size and book-tomarket. In Section 4.2, we examine the returns to quintile portfolios sorted by idiosyncratic volatility, beginning with individual stocks and then the Fama-French portfolios formed on size and book-to-market. Then, in Section 4.3, we use Fama-MacBeth regressions to determine if idiosyncratic risk is priced for portfolios while controlling for other potential explanatory variables. In Section 4.4, we provide various robustness checks for our initial findings using alternative samples.

\subsection{Descriptive Statistics and Correlation Matrix}

Table 1 presents descriptive statistics for the 100 portfolios (Panel A) and 25 portfolios (Panel B) formed on size and book-to-market. The statistics are generated by computing the time-series averages of the monthly cross-sectional mean, standard deviation, 25th percentile, 50 th percentile, and 75th percentile of the respective variables. Between the two sets of portfolios, the mean returns, average firm size, book-to-market ratios, and factor loadings are similar. However, the standard deviation of returns and the four factor loadings tend to be larger for the less diversified portfolios. Additionally, the mean and standard deviation

\footnotetext{
${ }^{17}$ Following Ben-David et al. (2014), who investigate the effect of the presence of ETFs on the volatility of their underlying stocks, we restrict our sample to ETFs that primarily invest in US domestic equity stocks by filtering using the Lipper Objective Codes presented in their paper. We note that the remaining sample after filtering still includes some leveraged ETFs, inverse ETFs, and ETFs investing in foreign, non-equity, or derivative securities. Therefore, we filter out these funds based on key words appearing in the fund name, such as "Global," "Ultra," "2x," "Short," "Commodity," and "Currency". We restrict our sample to the following Lipper Objective Codes: Broad Based US Equity Funds: S\&P 500 Index Objective Funds, Mid-Cap Funds, Small-Cap Funds, Micro-Cap Funds, Capital Appreciation Funds, Growth Funds, Growth and Income Funds, and Equity Income Funds (SP, MC, SG, MR, CA, G, GI, and EI respectively). US Sector Funds investing in equities: Basic Materials, Consumer Goods, Consumer Services, Financial Services, Health/Biotechnology, Industrials, Natural Resources, Real Estate, Science and Technology, Telecommunications, Specialty/Miscellaneous Funds, and Utilities (BM, CG, CS, FS, H, ID, NR, RE, TK, TL, S, and UT, respectively).
} 
of estimated idiosyncratic volatility is $0.694 \%$ for the 100 portfolios and $0.380 \%$ for the 25 portfolios, reflecting lower idiosyncratic risk in more diversified portfolios. In both groups, the average portfolio has a market beta of approximately one, positive loadings on the size and book-to-market risk factors, and a slight negative loading on the momentum risk factor. For informational purposes, we also present the time-series averages of the monthly crosssectional statistics for the number of firms within the portfolio. In general, the portfolios containing the smallest stocks have a much larger number of stocks within the portfolio, resulting in a high standard deviation and a mean above the 75 th percentile.

Table 2 presents the time-series averages of cross-sectional correlations for all variables with the addition of the lagged return. On average, the monthly cross-sectional correlation between return and lagged idiosyncratic volatility is negative for both sets of portfolios. The correlation coefficient is -0.025 among the 100 portfolios and -0.036 among the 25 portfolios. In comparison, the average monthly cross-sectional correlation between individual stock return and lagged idiosyncratic volatility is -0.020 , lower in magnitude than that of either of the two sets of portfolios. Upon further investigation, we attribute this finding to a strong negative correlation in the data for the Fama-French portfolios for months before July 1963. ${ }^{18}$ After July 1963, the negative correlation between return and lagged idiosyncratic volatility is stronger for stocks than for the Fama-French portfolios. ${ }^{19}$ Nevertheless, the overall results suggest a negative but weak idiosyncratic volatility-return correlation. We also note a negative correlation between size and idiosyncratic volatility. When we sort assets based on idiosyncratic volatility, the group of assets with the highest idiosyncratic volatility tends to constitute the smallest proportion of the value of the market.

\subsection{Quintile Portfolio Sorting on Idiosyncratic Volatility}

We begin our formal analysis with portfolio sorting ranked on idiosyncratic volatility. For every month, assets are sorted into quintile portfolios on the basis of lagged values of idiosyncratic volatility. Each quintile portfolio contains an equal number of assets. The

\footnotetext{
${ }^{18}$ Throughout the paper, we use July 1963 as a breakpoint in our sample because it is the starting date of the related tests in Ang et al. (2006) as well as the tests in Fama and French (1992, 1993) and several other related studies. CRSP data prior to 1963 includes only NYSE stocks; AMEX and NASDAQ data begins in 1963 and 1973, respectively.

${ }^{19}$ We compute the average monthly cross-sectional correlation between return and lagged idiosyncratic volatility for all months before July 1963. Compared to the full sample period, the correlation for stocks over this time period is relatively similar (-0.022), while the correlation for the 100 portfolios and 25 portfolios are more negative (-0.061 and -0.080 , respectively). When we compute the average monthly cross-sectional correlation for all months from July 1963 onward, the correlation for stocks is -0.018 , while the correlations for the 100 portfolios and 25 portfolios are 0.001 and -0.003 , respectively.
} 
assets within each of the resulting five portfolios are value weighted to form a time-series of monthly returns. We also construct a zero-investment arbitrage portfolio which is equivalent to investing in the highest idiosyncratic volatility portfolio and short-selling the lowest idiosyncratic volatility portfolio (high minus low portfolio). For each quintile portfolio, we report the average monthly return as well as a measure of risk-adjusted return represented by Jensen's alpha with respect to the CAPM, Fama and French (1993) three factor model and Carhart (1997) four factor model. The primary estimate of interest is the risk-adjusted average return to the high minus low portfolio. Finding a risk-adjusted average return that is economically and statistically significant different from zero for this portfolio would have tradeable implications. To account for heteroskedasticity and autocorrelation, Newey and West (1987) standard errors are calculated with a maximum lag order of six months.

We start by replicating the findings of AHXZ to illustrate the negative relation between lagged idiosyncratic volatility and average returns of stocks. To ensure comparability to the results presented by AHXZ, we initially restrict the sample to July 1963 to December 2000. Table 3 presents the value weighted returns of quintile portfolios formed by sorting the NYSE, AMEX, and NASDAQ stocks based on idiosyncratic volatility. The value-weighted average return differential between the highest and lowest idiosyncratic volatility portfolios is $-1.059 \%$ (t-statistic of -3.12). This result is similar to the finding of AHXZ (in their Table VI): $-1.06 \%$ value-weighted average return differential and t-statistic of -3.10 . The FF3 alpha of the high minus low portfolio is $-1.356 \%$ with a t-statistic of -7.22 ; AHXZ report an FF3 alpha of $-1.31 \%$ and an associated t-statistic of -7.00. The negative relation seems to come from abnormally low average returns for high idiosyncratic volatility stocks rather than high average returns for low idiosyncratic volatility stocks. Additionally, we check whether the previous findings may have been due in part to the specific time period by performing the sorting analysis using the sample of stocks from November 1926 to June 2013. Over this wider time frame, the negative relation still persists as the high minus low portfolio produces an FF3 alpha of $-1.029 \%$ and a t-statistic of -7.28. Even after using the Carhart (1997) model to account for exposure to the momentum risk factor, both samples show an economically and statistically significant negative FF4 alpha.

In their paper, AHXZ utilize the following double sorting methodology. First, stocks are sorted into quintile portfolios ranked on a characteristic, such as size. Then, within each characteristic quintile, the stocks are sorted again into quintile portfolios ranked on IVOL to produce 25 portfolios. This allows for examination of the IVOL-return relation at various levels of the characteristic. Finally, averaging across the five characteristic portfolios within 
each IVOL quintile produces quintile portfolios with dispersion in IVOL, but each quintile contains stocks that span the entire range of the characteristic. They use this double sorting approach to control for various stock characteristics. Our approach is similar in that we begin with portfolios of stocks which are formed based on certain characteristics (size and book-to-market ratio). However, rather than sorting the individual stocks within each of these portfolios, we treat the entire portfolio as an asset and sort the portfolios based on the idiosyncratic volatility of each portfolio's return.

We perform the sorting procedure for the 100 portfolios and 25 portfolios formed on size and book-to-market over the same two time periods. Table 4 presents the results of the analysis from sorting the 100 portfolios into quintiles based on idiosyncratic volatility. From July 1963 to December 2000, the high minus low portfolio has an FF3 alpha and t-statistic of $-0.156 \%$ and -1.30 , respectively. Similarly, the FF4 alpha and associated t-statistic is $-0.161 \%$ and -1.24. In comparison to the results from using individual stocks, the high minus low portfolio created from the 100 portfolios is much smaller in magnitude and is not statistically significant. When we extend the analysis to the longer time period in Panel B, we find a statistically significant FF3 alpha of $-0.240 \%$. Nevertheless, the magnitude of the negative relation between idiosyncratic volatility and return is much smaller compared to that of individual stocks. Furthermore, after we control for exposure to the momentum risk factor, the FF4 alpha is $-0.159 \%$ and is only marginally statistically significant at the $10 \%$ level. Table 5 presents the results of the analysis from sorting the 25 portfolios into quintiles based on idiosyncratic volatility. As with the 100 portfolios, we fail to find an economically and statistically significant relation between idiosyncratic volatility and risk-adjusted returns. As the level of diversification increases from individual stocks to 100 portfolios to 25 portfolios, we see that the statistical significance and magnitude of the negative relation diminishes monotonically.

In their analysis, AHXZ note that while the fifth quintile contains the highest $20 \%$ of stocks sorted by idiosyncratic volatility, the portfolio constitutes less than $2 \%$ of the value of the market on average. We find a similar result in Table 3 over both time periods. This reflects a strong negative correlation between size and idiosyncratic volatility, i.e., smaller firms tend to have higher idiosyncratic volatility. For our individual stock sample, the average correlation between idiosyncratic volatility and the natural log of firm size is -0.463 . From Table 2, we see that this negative correlation exists for portfolios as well, but it is relatively weaker (-0.163 and -0.152 for the 100 and 25 portfolio samples, respectively). As we would expect, the quintile portfolios formed on idiosyncratic volatility are slightly more balanced 
with respect to market share for the portfolio data sets compared to the individual stock sample.

\subsection{Fama-MacBeth Cross-sectional Regressions}

We estimate the pricing of idiosyncratic volatility for portfolios using a series of two-stage Fama and MacBeth (1973) cross-sectional regressions. This type of analysis can provide additional information beyond quintile portfolio sorting as it allows us to control for factor loadings and other characteristics. In the first stage, we perform monthly cross-sectional regressions of excess return in month $t$ onto idiosyncratic volatility and other control variables in month $t-1$. In the second stage, we calculate the time-series average of the cross-sectional regression coefficients and test whether the average coefficient is significantly different from zero using Newey-West t-statistics with six lags. In Table 6 and 7, the results from using the sample from July 1963 to December 2000 and November 1926 to June 2013 are reported in Panel A and Panel B, respectively. Model 1 is a univariate model of excess return regressed on lagged idiosyncratic volatility. Model 2 includes controls for portfolio characteristics (reversal, momentum, and the natural log of average firm size and book-to-market). Model 3 adds the estimated time-series of the four factor loadings as additional controls. Specifically, the cross-sectional model (including all control variables) is as follows:

$$
\begin{aligned}
r_{i t} & =a_{t}+b_{1 t} I V O L_{i(t-1)} \\
& +b_{2 t} r_{i(t-1)}+b_{3 t} r_{i(t-7, t-2)}+b_{4 t} \ln (S I Z E)_{i(t-1)}+b_{5 t} \ln (B / M)_{i(t-1)} \\
& +b_{6 t} \beta_{i(t-1)}^{M K T}+b_{7 t} \beta_{i(t-1)}^{S M B}+b_{8 t} \beta_{i(t-1)}^{H M L}+b_{9 t} \beta_{i(t-1)}^{U M D}+e_{i t} .
\end{aligned}
$$

Under the null hypothesis of a correctly specified factor model, the coefficient on idiosyncratic volatility in the model should be equal to zero. In each of the three models for both Fama-French portfolio samples, we do not find statistically significant evidence that the coefficient on idiosyncratic volatility is different from zero. We report the average of the adjusted $R^{2}$ from the cross-sectional regressions at the bottom of the tables. The included control variables seem to explain more of the cross-sectional variation in excess returns for the 25 portfolios than for the 100 portfolios. For both portfolio data sets, the coefficient on $\ln (\mathrm{B} / \mathrm{M})$ is positive and statistically significant across the various models and time periods. Return reversal appears to have explanatory power for the 100 portfolios over the full sample period, while the six month compound return from month $t-7$ to $t-2$ carries a small but positive coefficient that is statistically significant for both portfolio data sets from July 1963 
to December 2000.

\subsection{Robustness Checks}

We provide further supportive evidence in the following robustness checks. First, we perform sorting and Fama-MacBeth regression analyses using alternate samples for 49 industry portfolios and exchange traded funds. We also reperform all analyses involving Fama-French portfolios using equal weighted portfolio returns and alternative sample periods. The resulting tables are included in the Appendix (Table A8 through A17).

Table A8 presents the results from sorting the 49 industry portfolios into quintiles based on idiosyncratic volatility. From July 1963 to December 2000, we fail to find a significant relation between idiosyncratic volatility and risk-adjusted returns. From November 1926 to June 2013, the FF3 alpha and FF4 alpha of $-0.228 \%$ and $-0.230 \%$ are statistically significant at the $10 \%$ level. This result seems to be attributable to data before July 1963. Table A9 presents the results of Fama-MacBeth cross-sectional regressions. In Model 3B, the coefficient on idiosyncratic volatility is $-0.183 \%$ and significant at the $5 \%$ level. Across both time periods, the lagged return and the six month compound return from month $t-7$ to $t-2$ have significant explanatory power for the excess returns of the industry portfolios. Because these portfolios group together stocks within the same industry, we would expect that there would be a higher degree of cross-correlation among the stocks within each portfolio compared to that of the 25 portfolios or even the 100 portfolios data sets. This correlation causes portfolio risk to diminish less rapidly as diversification increases. As expected, we observe higher estimated idiosyncratic volatility for the industry portfolios compared to the other Fama-French portfolios. If the negative IVOL-return relation is due to idiosyncratic risk characteristics rather than systematic risk, then it would make sense that we observe more evidence of a negative relation for industry portfolios as these portfolios will retain more exposure to risk specific to each industry.

We also investigate the relation between idiosyncratic volatility and returns using exchange traded funds as test assets. Unlike the Fama-French portfolios which are formed artificially, exchange traded funds are portfolios of assets that are actively traded. Like mutual funds, ETFs hold an underlying portfolio of securities and provide investors with access to a wide range of investment strategies, markets, and types of assets. However, while openend mutual fund shares are purchased or sold at their end-of-day net asset value, ETF shares can be traded intraday like stocks, and their prices are determined based on trading activity. ETFs issue shares in large blocks called creation units. Institutional investors may purchase 
and redeem creation units in exchange for shares of underlying securities (structured in proportion to the fund's portfolio), cash, or both. The creation units are then divided into shares to be sold to retail investors on a secondary market. The ability to exchange creation units directly for shares of the underlying securities facilitates arbitrage which, on average, will minimize deviations between market price and the net asset value. Therefore, we expect that the returns for shares of exchange traded funds should closely resemble the potential returns for directly holding proportional shares of the assets in the underlying portfolio.

Table A10 presents the results of sorting the ETF samples into quintiles based on idiosyncratic volatility. Value weighted quintile returns are calculated on the basis of the market capitalization of the ETF in month $t-1$, but the results are robust to the use of equal weighted quintile returns. ${ }^{20}$ Using both samples of ETFs, we fail to find evidence of a relation between idiosyncratic volatility and returns. Additionally, we present the results of Fama-MacBeth regressions in Table A11. Using controls for return reversal, return momentum, the natural log of the market capitalization of the fund, and the four factor loadings, we do not find a statistically significant coefficient on idiosyncratic volatility.

The Fama-French portfolio data sets also include equal weighted daily and monthly portfolio returns. We perform quintile portfolio sorting and Fama-MacBeth regressions using this data. The results are presented in Table A12 through A17 and are generally consistent with our previous conclusions. We also consider using an equal weighting scheme to calculate quintile returns in our sorting analyses using both the value weighted and equal weighted returns of the three Fama-French portfolio data sets. We do not report the results in this paper, but they are available upon request. We find some evidence of a negative relation between idiosyncratic volatility and return when creating equal weighted quintile portfolios of value weighted returns, but the results are not robust to alternative time periods. ${ }^{21}$ The negative IVOL-return relation disappears when using value weighted quintile returns, as shown in our primary analysis. We note that when we use equal weighting to calculate quintile portfolio returns for individual stocks from July 1963 to December 2000, the economic and statistical significance of the negative relation is diminished (FF3 alpha of $-0.502 \%$ and t-statistic of -2.17 using equal weighting compared to FF3 alpha of $-1.356 \%$ and t-statistic

\footnotetext{
${ }^{20}$ When calculating value weighted quintile returns, we weight returns using market capitalization for individual stocks and average firm size for the Fama-French portfolios. However, the value weighting methodology used for ETFs has a slightly different interpretation as there is not necessarily a direct relationship between the size (market capitalization) of the ETF and the size of the securities in which the ETF invests.

${ }^{21}$ We reperformed all sorting and Fama-MacBeth regression analyses for the Fama-French portfolio samples and the individual stock sample using a sample period of November 1926 to June 1963 and July 1963 to June 2013. The results were qualitatively unchanged.
} 
of -7.22 using value weighting). Therefore, it seems more appropriate to use value weighting to calculate quintile portfolio returns for our sorting analyses so that our methodology and results are comparable to the IVOL puzzle initially identified by AHXZ.

\section{Conclusion}

In this paper, we present empirical evidence to address the hypothesis that the negative cross-sectional relation between idiosyncratic volatility and expected stock returns is due to a misspecified model and a missing risk factor. Since the formation of a diversified portfolio reduces idiosyncratic risk but not systematic risk, we use a variety of portfolios as test assets to investigate whether the IVOL puzzle still exists for portfolios of stocks.

We do not find economically or statistically significant and robust evidence of a relation between idiosyncratic volatility and portfolio returns. Using value weighted quintile portfolio sorting on the basis of lagged idiosyncratic volatility, the negative relation for NYSE, AMEX, and NASDAQ stocks from July 1963 to December 2000 does not persist when these stocks are grouped into portfolios based on size and book-to-market. Across alternative sample periods, we find that the risk-adjusted return differential between the high IVOL and low IVOL portfolios diminishes in economic and statistical significance as the level of diversification increases. We also measure the effect of idiosyncratic volatility on returns by performing twostage Fama-MacBeth regressions and do not find evidence that the coefficient on idiosyncratic volatility is different from zero for portfolios of stocks. Our findings are robust to the use of equal weighted portfolio returns, alternate samples of portfolios, and varying time periods.

Additional research can be focused towards further investigation of the existing evidence of a missing risk factor to reconcile the apparent contradiction stemming from these results. If we rule out the explanation for the IVOL puzzle of a missing risk factor, this leaves the explanations related to firm-specific characteristics. Still, the literature on the determinants of the pricing of idiosyncratic volatility continues to grow in search of a comprehensive and conclusive explanation. To reinforce the arguments made in this paper, we can simulate a data generating process in which assets load on a specified risk factor and demonstrate that exposure to the risk factor persists when we combine these assets into portfolios. Another potential extension involves determining the level of diversification at which the mispricing is no longer significant and to what degree the method of portfolio formation matters. We could assign stocks to portfolios in a gradual manner and investigate the impact on the negative IVOL-return relation. In addition, we could use alternate portfolio samples formed 
on other characteristics in order to increase the power of our conclusions. While our findings do not introduce a new explanation for the IVOL puzzle, we contribute to the literature on idiosyncratic risk by providing empirical evidence against the particular explanation of idiosyncratic volatility proxying for a missing risk factor. 


\section{References}

Ang, A., R. J. Hodrick, Y. Xing, and X. Zhang (2006). The cross-section of volatility and expected returns. Journal of Finance 61, 259-299.

Ang, A., R. J. Hodrick, Y. Xing, and X. Zhang (2009). High idiosyncratic volatility and low returns: International and further U.S. evidence. Journal of Financial Economics 91, $1-23$.

Bali, T. G. and N. Cakici (2008). Idiosyncratic volatility and the cross section of expected returns. Journal of Financial and Quantitative Analysis 43, 29-58.

Bali, T. G., N. Cakici, and R. F. Whitelaw (2011). Maxing out: Stocks as lotteries and the cross-section of expected returns. Journal of Financial Economics 99, 427-446.

Bali, T. G., N. Cakici, X. Yan, and Z. Zhang (2005). Does idiosyncratic risk really matter? Journal of Finance 60, 905-929.

Barberis, N. and M. Huang (2008). Stocks as lotteries: The implications of probability weighting for security prices. American Economic Review 98, 2066-2100.

Ben-David, I., F. Franzoni, and R. Moussawi (2014). Do ETFs increase volatility? Working Paper, Ohio State University.

Black, F. (1972). Capital market equilibrium with restricted borrowing. Journal of Business 45, 444-455.

Boehme, R. D., B. R. Danielsen, P. Kumar, and S. M. Sorescu (2009). Idiosyncratic risk and the cross-section of stock returns: Merton (1987) meets Miller (1977). Journal of Financial Markets 12, 438-468.

Boyer, B., T. Mitton, and K. Vorkink (2010). Expected idiosyncratic skewness. Review of Financial Studies 23, 169-202.

Carhart, M. (1997). On persistence in mutual fund performance. Journal of Finance 52, $57-82$.

Chabi-Yo, F. and J. Yang (2010). Default risk, idiosyncratic coskewness and equity returns. Working Paper, Ohio State University. 
Chen, Z. and R. Petkova (2014). Does idiosyncratic volatility proxy for risk exposure? Review of Financial Studies 25, 2745-2787.

Duarte, J., A. Kamara, S. Siegel, and C. Sun (2014). The systematic risk of idiosyncratic volatility. Working Paper.

Fama, E. F. and K. R. French (1992). The cross-section of expected stock returns. Journal of Finance 47, 427-465.

Fama, E. F. and K. R. French (1993). Common risk factors in the returns on stocks and bonds. Journal of Financial Economics 33, 3-56.

Fama, E. F. and J. D. MacBeth (1973). Risk, return, and equilibrium: Empirical tests. Journal of Political Economy 81, 607-636.

Fu, F. (2009). Idiosyncratic risk and the cross-section of expected stock returns. Journal of Financial Economics 91, 24-37.

Goyal, A. and P. Santa-Clara (2003). Idiosyncratic risk matters! Journal of Finance 58, $975-1007$.

Guo, H. and R. Savickas (2006). Idiosyncratic volatility, stock market volatility, and expected stock returns. Journal of Business and Economic Statistics 24, 43-56.

Guo, H. and R. Savickas (2008). Average idiosyncratic volatility in G7 countries. Review of Financial Studies 21, 1259-1296.

Han, B. and A. Kumar (2013). Speculative trading and asset prices. Journal of Financial and Quantitative Analysis 48, 377-404.

Herskovic, B., B. Kelly, H. Lustig, and S. V. Nieuwerburgh (2014). The common factor in idiosyncratic volatility: Quantitative asset pricing implications. Working paper, New York University.

Hou, K. and R. Loh (2014). Have we solved the idiosyncratic volatility puzzle? Working Paper, Ohio State University.

Huang, W., Q. Liu, S. G. Rhee, and L. Zhang (2009). Return reversals, idiosyncratic risk, and expected returns. Review of Financial Studies 23, 147-168. 
Jiang, G. J., D. Xu, and T. Yao (2009). The information content of idiosyncratic volatility. Journal of Financial and Quantitative Analysis 44, 1-28.

Johnson, T. C. (2004). Forecast dispersion and the cross-section of stock returns. Journal of Finance 59, 1957-1978.

Levy, H. (1978). Equilibrium in an imperfect market: A constraint on the number of securities in the portfolio. The American Economic Review 68, 643-658.

Lintner, J. (1965). The valuation of risk assets and the selection of risky investments in stock portfolios and capital budgets. The Review of Economics and Statistics 47, 13-37.

MacKinlay, A. C. (1995). Multifactor models do not explain deviations from the CAPM. Journal of Financial Economics 38, 3-28.

Malkiel, B. G. and Y. Xu (2006). Idiosyncratic risk and security returns. Working paper, The University of Texas at Dallas.

Merton, R. C. (1987). A simple model of capital market equilibrium with incomplete information. Journal of Finance XLII, 483-510.

Newey, W. K. and K. D. West (1987). A simple, positive semi-definite, heteroskedasticity and autocorrelation consistent covariance matrix. Econometrica 55, 703-708.

Sharpe, W. F. (1964). Capital asset prices: A theory of market equilibrium under conditions of risk. Journal of Finance 19, 425-442.

Wei, S. X. and C. Zhang (2005). Idiosyncratic risk does not matter: A re-examination of the relationship between average returns and average volatilities. Journal of Banking and Finance 29, 603-621.

Wong, P. (2011). Earnings shocks and the idiosyncratic volatility discount in the cross-section of expected returns. Working Paper, Ohio State University. 


\section{Tables}

Table 1: Descriptive Statistics

Panel A: 100 Portfolios Formed on Size and B/M

\begin{tabular}{lccccc}
\hline & Mean & Std. Dev. & Q1 & Median & Q3 \\
\hline Return(\%) & 1.208 & 4.018 & -1.113 & 1.038 & 3.341 \\
Excess Return(\%) & 0.919 & 4.018 & -1.402 & 0.749 & 3.052 \\
Return(-7,-2)(\%) & 7.626 & 10.406 & 1.148 & 6.977 & 13.419 \\
IVOL(\%) & 0.694 & 0.470 & 0.433 & 0.573 & 0.786 \\
$\ln (\mathrm{SIZE})$ & 4.802 & 1.597 & 3.704 & 4.725 & 5.838 \\
$\ln (\mathrm{B} / \mathrm{M})$ & -0.146 & 0.736 & -0.602 & -0.131 & 0.308 \\
$\beta_{M K T}$ & 1.005 & 0.546 & 0.712 & 0.987 & 1.279 \\
$\beta_{S M B}$ & 0.560 & 0.863 & 0.066 & 0.534 & 1.032 \\
$\beta_{H M L}$ & 0.250 & 0.836 & -0.194 & 0.222 & 0.672 \\
$\beta_{U M D}$ & -0.017 & 0.704 & -0.361 & -0.008 & 0.338 \\
$\#$ Firms & 26 & 34 & 10 & 15 & 25 \\
\hline
\end{tabular}

Panel B: 25 Portfolios Formed on Size and B/M

\begin{tabular}{lrrrrr}
\hline & Mean & Std. Dev. & Q1 & Median & Q3 \\
\hline Return(\%) & 1.181 & 2.662 & -0.397 & 1.157 & 2.711 \\
Excess Return(\%) & 0.892 & 2.662 & -0.686 & 0.868 & 2.422 \\
Return(-7,-2)(\%) & 7.463 & 7.296 & 2.945 & 7.317 & 11.916 \\
IVOL(\%) & 0.380 & 0.254 & 0.246 & 0.316 & 0.415 \\
$\ln ($ SIZE) & 4.840 & 1.657 & 3.889 & 4.731 & 5.655 \\
$\ln (\mathrm{B} / \mathrm{M})$ & -0.134 & 0.721 & -0.505 & -0.133 & 0.224 \\
$\beta_{M K T}$ & 1.009 & 0.300 & 0.840 & 0.996 & 1.165 \\
$\beta_{S M B}$ & 0.528 & 0.607 & 0.171 & 0.557 & 0.905 \\
$\beta_{H M L}$ & 0.244 & 0.531 & -0.053 & 0.227 & 0.530 \\
$\beta_{U M D}$ & -0.010 & 0.373 & -0.199 & -0.006 & 0.187 \\
$\#$ Firms & 102 & 104 & 43 & 64 & 94 \\
\hline
\end{tabular}

The table reports the time-series averages of the monthly cross-sectional mean, standard deviation, 25th percentile, 50th percentile, and 75th percentile of the following variables for the two data sets used in the primary analysis. "Return" is the value weighted monthly portfolio return in month $t$. "Excess Return" is the return minus the monthly risk-free rate (one-month Treasury bill rate) in month $t$. "Return $(-7,-2)$ " is the buy-and-hold month $t-7$ to $t-2$ return. "IVOL" is the standard deviation of residuals from a regression of daily excess returns in month $t-1$ on the Fama and French (1993) model. "ln(SIZE)" is the natural $\log$ of the average firm size in the portfolio in month $t-1$. " $\ln (\mathrm{B} / \mathrm{M})$ " is the natural log of the value weighted book-to-market ratio of the portfolio in month $t-1$. " $\beta_{M K T}$," " $\beta_{S M B}$," " $\beta_{H M L}$," and " $\beta_{U M D}$ " are the loadings in month $t-1$ on the market, size, book-to-market, and momentum risk factors of the Carhart (1997) four factor model estimated every month using daily data. "\# Firms" is the number of firms in the portfolio. The full sample period for both data sets is November 1926 to June 2013. 
Table 2: Correlation Matrix

Panel A: 100 Portfolios Formed on Size and B/M

\begin{tabular}{|c|c|c|c|c|c|c|c|c|c|c|c|}
\hline & Return & Ex Ret & $\operatorname{Ret}(-1)$ & $\operatorname{Ret}(-7,-2)$ & IVOL & $\ln (\mathrm{SIZE})$ & $\ln (\mathrm{B} / \mathrm{M})$ & $\beta_{M K T}$ & $\beta_{S M B}$ & $\beta_{H M L}$ & $\beta_{U M D}$ \\
\hline Return & 1.000 & & & & & & & & & & \\
\hline Excess Return & 1.000 & 1.000 & & & & & & & & & \\
\hline $\operatorname{Return}(-1)$ & 0.008 & 0.008 & 1.000 & & & & & & & & \\
\hline $\operatorname{Return}(-7,-2)$ & 0.033 & 0.033 & 0.026 & 1.000 & & & & & & & \\
\hline IVOL & -0.025 & -0.025 & 0.050 & -0.047 & 1.000 & & & & & & \\
\hline $\ln (\mathrm{SIZE})$ & 0.003 & 0.003 & 0.004 & 0.028 & -0.163 & 1.000 & & & & & \\
\hline $\ln (\mathrm{B} / \mathrm{M})$ & 0.041 & 0.041 & 0.041 & 0.105 & 0.059 & -0.053 & 1.000 & & & & \\
\hline$\beta_{M K T}$ & -0.015 & -0.015 & 0.023 & -0.008 & 0.133 & 0.054 & -0.008 & 1.000 & & & \\
\hline$\beta_{S M B}$ & -0.018 & -0.018 & 0.018 & -0.013 & 0.080 & -0.500 & -0.039 & 0.223 & 1.000 & & \\
\hline$\beta_{H M L}$ & -0.001 & -0.001 & 0.031 & 0.047 & 0.066 & -0.002 & 0.416 & 0.105 & 0.104 & 1.000 & \\
\hline$\beta_{U M D}$ & 0.003 & 0.003 & 0.011 & 0.115 & -0.025 & 0.020 & -0.013 & -0.067 & -0.015 & 0.045 & 1.000 \\
\hline
\end{tabular}

Panel B: 25 Portfolios Formed on Size and B/M

\begin{tabular}{|c|c|c|c|c|c|c|c|c|c|c|c|}
\hline & Ret & Ex Ret & $\operatorname{Ret}(-1)$ & $\operatorname{Ret}(-7,-2)$ & IVOL & $\ln (\mathrm{SIZE})$ & $\ln (\mathrm{B} / \mathrm{M})$ & $\beta_{M K T}$ & $\beta_{S M B}$ & $\beta_{H M L}$ & $\beta_{U M D}$ \\
\hline Return & 1.000 & & & & & & & & & & \\
\hline Excess Return & 1.000 & 1.000 & & & & & & & & & \\
\hline Return(-1) & 0.063 & 0.063 & 1.000 & & & & & & & & \\
\hline $\operatorname{Return}(-7,-2)$ & 0.050 & 0.050 & 0.053 & 1.000 & & & & & & & \\
\hline IVOL & -0.036 & -0.036 & 0.004 & -0.065 & 1.000 & & & & & & \\
\hline $\ln (\mathrm{SIZE})$ & 0.002 & 0.002 & 0.003 & 0.013 & -0.152 & 1.000 & & & & & \\
\hline $\ln (\mathrm{B} / \mathrm{M})$ & 0.058 & 0.058 & 0.058 & 0.146 & 0.010 & -0.079 & 1.000 & & & & \\
\hline$\beta_{M K T}$ & -0.039 & -0.039 & 0.011 & -0.029 & 0.164 & 0.064 & -0.015 & 1.000 & & & \\
\hline$\beta_{S M B}$ & -0.014 & -0.014 & 0.018 & -0.007 & 0.092 & -0.726 & -0.025 & 0.157 & 1.000 & & \\
\hline$\beta_{H M L}$ & 0.019 & 0.019 & 0.045 & 0.085 & 0.091 & -0.031 & 0.637 & 0.106 & 0.054 & 1.000 & \\
\hline$\beta_{U M D}$ & -0.001 & -0.001 & 0.009 & 0.135 & -0.011 & 0.023 & -0.010 & -0.053 & -0.008 & 0.034 & 1.000 \\
\hline
\end{tabular}

The table reports the time-series averages of the monthly cross sectional correlations of the following variables for the two data sets used in the primary analysis. "Return" is the value weighted monthly portfolio return in month $t$. "Excess Return" is the return minus the monthly risk-free rate (one-month Treasury bill rate) in month $t$. "Return(-1)" is the value weighted monthly portfolio return in month $t-1$. "Return(-7,-2)" is the buy-and-hold month $t-7$ to $t-2$ return. "IVOL" is the standard deviation of residuals from a regression of daily excess returns in month $t-1$ on the Fama and French (1993) model. "ln(SIZE)" is the natural log of the average firm size in the portfolio in month $t-1$. "ln $(\mathrm{B} / \mathrm{M})$ " is the natural log of the value weighted book-to-market ratio of the portfolio in month $t-1$. " $\beta_{M K T}, "$ " $\beta_{S M B}, "$ " $\beta_{H M L}$, " and " $\beta_{U M D}$ " are the loadings in month $t-1$ on the market, size, book-to-market, and momentum risk factors of the Carhart (1997) four factor model estimated every month using daily data. The full sample period for both data sets is November 1926 to June 2013. 
Table 3: Sorting of Individual Stocks (Replication of Results from Ang et al. (2006))

Panel A: July 1963 to December 2000

\begin{tabular}{lcccccc}
\hline & Low IVOL & 2 & 3 & 4 & High IVOL & H - L \\
\hline \% Market Share & 53.55 & 27.87 & 11.69 & 5.03 & 1.86 & \\
Average Return & 1.042 & 1.145 & 1.210 & 0.821 & -0.017 & $-1.059^{* * *}$ \\
& $(5.69)$ & $(5.26)$ & $(4.32)$ & $(2.42)$ & $(-0.04)$ & $(-3.12)$ \\
CAPM Alpha & 0.098 & 0.085 & 0.035 & -0.441 & -1.284 & $-1.382^{* * *}$ \\
& $(1.40)$ & $(1.74)$ & $(0.34)$ & $(-2.59)$ & $(-4.94)$ & $(-4.37)$ \\
FF3 Alpha & 0.039 & 0.066 & 0.063 & -0.395 & -1.317 & $-1.356^{* * *}$ \\
& $(0.88)$ & $(1.14)$ & $(0.82)$ & $(-3.84)$ & $(-8.17)$ & $(-7.22)$ \\
FF4 Alpha & 0.075 & 0.137 & 0.085 & -0.395 & -1.326 & $-1.401^{* * *}$ \\
& $(1.65)$ & $(2.53)$ & $(1.19)$ & $(-3.99)$ & $(-7.53)$ & $(-6.79)$ \\
\hline
\end{tabular}

Panel B: November 1926 to June 2013

\begin{tabular}{lcccccc}
\hline & Low IVOL & 2 & 3 & 4 & High IVOL & H - L \\
\hline \% Market Share & 55.21 & 26.00 & 11.49 & 5.27 & 2.02 & \\
Average Return & 0.954 & 0.993 & 1.044 & 0.829 & 0.395 & $-0.559^{* *}$ \\
& $(6.17)$ & $(4.99)$ & $(4.41)$ & $(3.02)$ & $(1.28)$ & $(-2.49)$ \\
CAPM Alpha & 0.121 & -0.017 & -0.084 & -0.353 & -0.784 & $-0.905^{* * *}$ \\
& $(3.25)$ & $(-0.48)$ & $(-1.34)$ & $(-3.14)$ & $(-4.51)$ & $(-4.49)$ \\
FF3 Alpha & 0.122 & -0.052 & -0.149 & -0.431 & -0.907 & $-1.029^{* * *}$ \\
& $(4.39)$ & $(-1.55)$ & $(-2.69)$ & $(-5.14)$ & $(-7.23)$ & $(-7.28)$ \\
FF4 Alpha & 0.096 & -0.002 & -0.031 & -0.287 & -0.771 & $-0.867^{* * *}$ \\
& $(3.26)$ & $(-0.07)$ & $(-0.59)$ & $(-3.15)$ & $(-4.88)$ & $(-4.95)$ \\
\hline
\end{tabular}

Value weighted quintile portfolios are formed every month by sorting stocks based on lagged idiosyncratic volatility measured relative to the Fama and French (1993) model using daily data. For each quintile portfolio, the table reports the time-series value weighted average return, CAPM alpha, Fama and French (1993) three factor alpha, and Carhart (1997) four factor alpha on a monthly basis in percentage points. The column labeled "H - L" reports the average return and alphas for a strategy that is long the portfolio of assets with the highest idiosyncratic volatility in the previous month and short the portfolio of assets with the lowest idiosyncratic volatility in the previous month. Newey and West (1987) heteroskedasticityautocorrelation robust t-statistics are reported in parentheses with six months lag. $10 \%(*), 5 \%(* *)$, and $1 \%(* * *)$ significance levels are denoted for the " $\mathrm{H}-\mathrm{L}$ " portfolio. 


\section{Table 4: Sorting of 100 Portfolios Formed on Size and B/M}

Panel A: July 1963 to December 2000

\begin{tabular}{lcccccc}
\hline & Low IVOL & 2 & 3 & 4 & High IVOL & H - L \\
\hline \% Market Share & 37.51 & 19.95 & 16.76 & 14.14 & 11.67 & \\
Average Return & 1.003 & 1.111 & 1.103 & 1.167 & 1.170 & 0.167 \\
& $(4.96)$ & $(5.54)$ & $(5.10)$ & $(5.74)$ & $(4.92)$ & $(1.25)$ \\
CAPM Alpha & -0.011 & 0.106 & 0.094 & 0.151 & 0.144 & 0.155 \\
& $(-0.23)$ & $(1.44)$ & $(1.02)$ & $(1.60)$ & $(1.20)$ & $(1.15)$ \\
FF3 Alpha & -0.008 & -0.016 & -0.073 & -0.064 & -0.164 & -0.156 \\
& $(-0.18)$ & $(-0.27)$ & $(-1.02)$ & $(-1.00)$ & $(-1.58)$ & $(-1.30)$ \\
FF4 Alpha & 0.027 & 0.023 & -0.017 & -0.038 & -0.134 & -0.161 \\
& $(0.51)$ & $(0.38)$ & $(-0.22)$ & $(-0.57)$ & $(-1.21)$ & $(-1.24)$ \\
\hline
\end{tabular}

Panel B: November 1926 to June 2013

\begin{tabular}{lcccccc}
\hline & Low IVOL & 2 & 3 & 4 & High IVOL & H - L \\
\hline \% Market Share & 52.81 & 17.32 & 12.80 & 9.89 & 7.36 & \\
Average Return & 0.896 & 1.064 & 1.136 & 1.051 & 1.129 & $0.232^{*}$ \\
& $(5.30)$ & $(5.36)$ & $(4.85)$ & $(4.70)$ & $(4.25)$ & $(1.66)$ \\
CAPM Alpha & 0.004 & 0.083 & 0.089 & 0.009 & 0.011 & 0.007 \\
& $(0.14)$ & $(1.28)$ & $(1.08)$ & $(0.10)$ & $(0.10)$ & $(0.06)$ \\
FF3 Alpha & 0.013 & -0.016 & -0.091 & -0.175 & -0.226 & $-0.240^{* * *}$ \\
& $(0.58)$ & $(-0.31)$ & $(-1.47)$ & $(-2.80)$ & $(-2.67)$ & $(-2.70)$ \\
FF4 Alpha & 0.025 & -0.014 & -0.006 & -0.193 & -0.134 & $-0.159^{*}$ \\
& $(0.95)$ & $(-0.27)$ & $(-0.10)$ & $(-2.70)$ & $(-1.59)$ & $(-1.78)$ \\
\hline
\end{tabular}

Using the value weighted monthly returns of 100 portfolios formed on size and book-to-market, value weighted quintile portfolios are formed every month by sorting the 100 portfolios based on lagged idiosyncratic volatility measured relative to the Fama and French (1993) model using daily data. For each quintile portfolio, the table reports the time-series value weighted average return, CAPM alpha, Fama and French (1993) three factor alpha, and Carhart (1997) four factor alpha on a monthly basis in percentage points. The column labeled "H - L" reports the average return and alphas for a strategy that is long the portfolio of assets with the highest idiosyncratic volatility in the previous month and short the portfolio of assets with the lowest idiosyncratic volatility in the previous month. Newey and West (1987) heteroskedasticity-autocorrelation robust t-statistics are reported in parentheses with six months lag. $10 \%(*), 5 \%(* *)$, and $1 \%(* * *)$ significance levels are denoted for the "H - L" portfolio. 


\section{Table 5: Sorting of 25 Portfolios Formed on Size and B/M}

Panel A: July 1963 to December 2000

\begin{tabular}{lcccccc}
\hline & Low IVOL & 2 & 3 & 4 & High IVOL & H - L \\
\hline \% Market Share & 33.49 & 18.12 & 17.18 & 15.93 & 15.28 & \\
Average Return & 1.001 & 1.145 & 1.087 & 1.136 & 1.283 & $0.282^{* *}$ \\
& $(4.85)$ & $(5.08)$ & $(4.99)$ & $(4.92)$ & $(5.99)$ & $(2.08)$ \\
CAPM Alpha & -0.041 & 0.112 & 0.072 & 0.118 & 0.272 & $0.313^{* *}$ \\
& $(-0.57)$ & $(1.12)$ & $(0.75)$ & $(1.18)$ & $(2.56)$ & $(2.28)$ \\
FF3 Alpha & -0.021 & -0.031 & -0.092 & -0.128 & 0.015 & 0.036 \\
& $(-0.28)$ & $(-0.38)$ & $(-1.21)$ & $(-1.54)$ & $(0.19)$ & $(0.29)$ \\
FF4 Alpha & 0.012 & 0.017 & -0.069 & -0.064 & 0.019 & 0.007 \\
& $(0.15)$ & $(0.19)$ & $(-0.80)$ & $(-0.75)$ & $(0.20)$ & $(0.05)$ \\
\hline
\end{tabular}

Panel B: November 1926 to June 2013

\begin{tabular}{lcccccc}
\hline & Low IVOL & 2 & 3 & 4 & High IVOL & H - L \\
\hline \% Market Share & 50.59 & 16.30 & 12.84 & 11.26 & 9.00 & \\
Average Return & 0.875 & 1.111 & 1.087 & 1.106 & 1.221 & $0.345^{* *}$ \\
& $(5.10)$ & $(5.26)$ & $(4.81)$ & $(4.65)$ & $(4.95)$ & $(2.45)$ \\
CAPM Alpha & -0.030 & 0.124 & 0.027 & 0.036 & 0.136 & 0.167 \\
& $(-0.83)$ & $(1.84)$ & $(0.36)$ & $(0.40)$ & $(1.16)$ & $(1.26)$ \\
FF3 Alpha & -0.005 & 0.020 & -0.155 & -0.176 & -0.089 & -0.084 \\
& $(-0.14)$ & $(0.41)$ & $(-2.89)$ & $(-2.53)$ & $(-0.95)$ & $(-0.81)$ \\
FF4 Alpha & 0.004 & 0.021 & -0.087 & -0.108 & -0.115 & -0.119 \\
& $(0.11)$ & $(0.41)$ & $(-1.54)$ & $(-1.53)$ & $(-1.30)$ & $(-1.20)$ \\
\hline
\end{tabular}

Using the value weighted monthly returns of 25 portfolios formed on size and book-to-market, value weighted quintile portfolios are formed every month by sorting the 25 portfolios based on lagged idiosyncratic volatility measured relative to the Fama and French (1993) model using daily data. For each quintile portfolio, the table reports the time-series value weighted average return, CAPM alpha, Fama and French (1993) three factor alpha, and Carhart (1997) four factor alpha on a monthly basis in percentage points. The column labeled "H - L" reports the average return and alphas for a strategy that is long the portfolio of assets with the highest idiosyncratic volatility in the previous month and short the portfolio of assets with the lowest idiosyncratic volatility in the previous month. Newey and West (1987) heteroskedasticity-autocorrelation robust t-statistics are reported in parentheses with six months lag. $10 \%(*), 5 \%(* *)$, and $1 \%(* *)$ significance levels are denoted for the " $\mathrm{H}-\mathrm{L}$ " portfolio. 


\section{Table 6: Fama-MacBeth Regressions: 100 Portfolios Formed on Size and B/M}

\begin{tabular}{|c|c|c|c|c|c|c|}
\hline & \multicolumn{3}{|c|}{ Panel A: July 1963 to December 2000} & \multicolumn{3}{|c|}{ Panel B: November 1926 to June 2013} \\
\hline & $1 \mathrm{~A}$ & $2 \mathrm{~A}$ & $3 \mathrm{~A}$ & 1B & $2 \mathrm{~B}$ & $3 \mathrm{~B}$ \\
\hline \multirow[t]{2}{*}{ IVOL } & 0.216 & -0.047 & -0.102 & 0.051 & -0.046 & -0.044 \\
\hline & $(1.10)$ & $(-0.35)$ & $(-0.84)$ & $(0.45)$ & $(-0.50)$ & $(-0.52)$ \\
\hline \multirow[t]{2}{*}{ Return $(-1)$} & & -0.008 & -0.006 & & $-0.037^{* * *}$ & $-0.029^{* * *}$ \\
\hline & & $(-0.92)$ & $(-0.77)$ & & $(-4.76)$ & $(-3.94)$ \\
\hline \multirow[t]{2}{*}{$\operatorname{Return}(-7,-2)$} & & $0.012^{* * *}$ & $0.011^{* * *}$ & & $0.006^{*}$ & $0.005^{*}$ \\
\hline & & $(2.93)$ & $(2.94)$ & & $(1.76)$ & $(1.68)$ \\
\hline \multirow[t]{2}{*}{$\ln (\mathrm{SIZE})$} & & -0.031 & -0.032 & & $-0.069^{* *}$ & $-0.059^{*}$ \\
\hline & & $(-0.69)$ & $(-0.65)$ & & $(-2.16)$ & $(-1.74)$ \\
\hline \multirow[t]{2}{*}{$\ln (\mathrm{B} / \mathrm{M})$} & & $0.222^{* *}$ & $0.268^{* * *}$ & & $0.205^{* * *}$ & $0.228^{* * *}$ \\
\hline & & $(2.27)$ & $(3.11)$ & & $(3.11)$ & $(3.83)$ \\
\hline \multirow[t]{2}{*}{$\beta_{M K T}$} & & & 0.110 & & & -0.003 \\
\hline & & & $(0.96)$ & & & $(-0.04)$ \\
\hline \multirow[t]{2}{*}{$\beta_{S M B}$} & & & 0.024 & & & 0.020 \\
\hline & & & $(0.41)$ & & & $(0.49)$ \\
\hline \multirow[t]{2}{*}{$\beta_{H M L}$} & & & $-0.111^{*}$ & & & $-0.099^{* *}$ \\
\hline & & & $(-1.84)$ & & & $(-2.12)$ \\
\hline \multirow[t]{2}{*}{$\beta_{U M D}$} & & & 0.086 & & & 0.065 \\
\hline & & & $(1.28)$ & & & $(1.18)$ \\
\hline \multirow[t]{2}{*}{ Constant } & $0.650^{* *}$ & $0.849^{* *}$ & $0.889^{* *}$ & $0.852^{* * *}$ & $1.070^{* * *}$ & $1.052^{* * *}$ \\
\hline & $(2.48)$ & $(2.06)$ & $(2.22)$ & $(4.13)$ & $(3.69)$ & $(3.88)$ \\
\hline $\operatorname{Adj} R^{2}$ & 0.025 & 0.301 & 0.334 & 0.052 & 0.263 & 0.317 \\
\hline
\end{tabular}

The table reports results from two-stage Fama and MacBeth (1973) regressions for 100 portfolios formed on size and book-to-market. Time-series averages of estimated coefficients from monthly cross-sectional regressions are presented. The dependent variable is the value weighted monthly portfolio return minus the monthly risk-free rate (one-month Treasury bill rate) in month $t$. "IVOL" is the standard deviation of residuals from a regression of daily excess returns in month $t-1$ on the Fama and French (1993) model. "Return(-1)" is the value weighted monthly portfolio return in month $t-1$. "Return $(-7,-2)$ " is the buy-and-hold month $t-7$ to $t-2$ return. "ln(SIZE)" is the natural $\log$ of the average firm size in the portfolio in month $t-1$. " $\ln (\mathrm{B} / \mathrm{M})$ " is the natural log of the value weighted book-to-market ratio of the portfolio in month $t-1$. " $\beta_{M K T}$, " $\beta_{S M B}$," " $\beta_{H M L}$," and " $\beta_{U M D}$ " are the loadings in month $t-1$ on the market, size, book-to-market, and momentum risk factors of the Carhart (1997) four factor model estimated every month using daily data. The average adjusted $R^{2}$ of the cross-sectional regressions is reported. The sample period is July 1963 to December 2000 for Panel A and November 1926 to June 2013 for Panel B. Newey and West (1987) heteroskedasticity-autocorrelation robust t-statistics are reported in parentheses with six months lag. $10 \%(*), 5 \%(* *)$, and $1 \%(* * *)$ significance levels are denoted. 


\section{Table 7: Fama-MacBeth Regressions: 25 Portfolios Formed on Size and B/M}

\begin{tabular}{|c|c|c|c|c|c|c|}
\hline & \multicolumn{3}{|c|}{ Panel A: July 1963 to December 2000} & \multicolumn{3}{|c|}{ Panel B: November 1926 to June 2013} \\
\hline & $1 \mathrm{~A}$ & $2 \mathrm{~A}$ & $3 \mathrm{~A}$ & $1 \mathrm{~B}$ & $2 \mathrm{~B}$ & $3 \mathrm{~B}$ \\
\hline \multirow[t]{2}{*}{ IVOL } & 0.213 & -0.241 & -0.128 & -0.046 & -0.233 & -0.098 \\
\hline & $(0.42)$ & $(-0.76)$ & $(-0.39)$ & $(-0.18)$ & $(-1.26)$ & $(-0.52)$ \\
\hline \multirow[t]{2}{*}{ Return $(-1)$} & & 0.023 & 0.021 & & $-0.024^{* *}$ & -0.017 \\
\hline & & $(1.42)$ & $(1.20)$ & & $(-2.16)$ & $(-1.51)$ \\
\hline \multirow[t]{2}{*}{$\operatorname{Return}(-7,-2)$} & & $0.013^{* *}$ & $0.017^{* * *}$ & & $0.009^{*}$ & $0.011^{* *}$ \\
\hline & & $(2.18)$ & $(2.74)$ & & $(1.88)$ & $(2.15)$ \\
\hline \multirow[t]{2}{*}{$\ln (\mathrm{SIZE})$} & & -0.026 & -0.013 & & $-0.065^{* *}$ & -0.050 \\
\hline & & $(-0.58)$ & $(-0.23)$ & & $(-1.98)$ & $(-1.29)$ \\
\hline \multirow[t]{2}{*}{$\ln (\mathrm{B} / \mathrm{M})$} & & $0.224^{* *}$ & $0.245^{* *}$ & & $0.206^{* * *}$ & $0.216^{* * *}$ \\
\hline & & $(2.16)$ & $(2.52)$ & & $(3.02)$ & $(3.48)$ \\
\hline \multirow[t]{2}{*}{$\beta_{M K T}$} & & & -0.119 & & & $-0.299^{* *}$ \\
\hline & & & $(-0.67)$ & & & $(-2.16)$ \\
\hline \multirow[t]{2}{*}{$\beta_{S M B}$} & & & 0.162 & & & 0.104 \\
\hline & & & $(1.45)$ & & & $(1.31)$ \\
\hline \multirow[t]{2}{*}{$\beta_{H M L}$} & & & -0.112 & & & -0.054 \\
\hline & & & $(-1.64)$ & & & $(-0.82)$ \\
\hline \multirow[t]{2}{*}{$\beta_{U M D}$} & & & -0.133 & & & -0.044 \\
\hline & & & $(-1.29)$ & & & $(-0.46)$ \\
\hline \multirow[t]{2}{*}{ Constant } & $0.688^{* *}$ & $0.787^{*}$ & $0.955^{* *}$ & $0.903^{* * *}$ & $0.931^{* * *}$ & $1.122^{* * *}$ \\
\hline & $(2.42)$ & $(1.87)$ & $(2.33)$ & $(4.22)$ & $(3.21)$ & $(3.79)$ \\
\hline $\operatorname{Adj} R^{2}$ & 0.033 & 0.499 & 0.550 & 0.086 & 0.455 & 0.527 \\
\hline
\end{tabular}

The table reports results from two-stage Fama and MacBeth (1973) regressions for 25 portfolios formed on size and book-to-market. Time-series averages of estimated coefficients from monthly cross-sectional regressions are presented. The dependent variable is the value weighted monthly portfolio return minus the monthly risk-free rate (one-month Treasury bill rate) in month $t$. "IVOL" is the standard deviation of residuals from a regression of daily excess returns in month $t-1$ on the Fama and French (1993) model. "Return(-1)" is the value weighted monthly portfolio return in month $t-1$. "Return $(-7,-2)$ " is the buy-and-hold month $t-7$ to $t-2$ return. " $\ln (\mathrm{SIZE})$ " is the natural $\log$ of the average firm size in the portfolio in month $t-1$. " $\ln (\mathrm{B} / \mathrm{M})$ " is the natural log of the value weighted book-to-market ratio of the portfolio in month $t-1$. " $\beta_{M K T}$, " $\beta_{S M B}$," " $\beta_{H M L}$," and " $\beta_{U M D}$ " are the loadings in month $t-1$ on the market, size, book-to-market, and momentum risk factors of the Carhart (1997) four factor model estimated every month using daily data. The average adjusted $R^{2}$ of the cross-sectional regressions is reported. The sample period is July 1963 to December 2000 for Panel A and November 1926 to June 2013 for Panel B. Newey and West (1987) heteroskedasticity-autocorrelation robust t-statistics are reported in parentheses with six months lag. $10 \%(*), 5 \%(* *)$, and $1 \%(* * *)$ significance levels are denoted. 


\section{Appendix}

Table A8: Sorting of 49 Industry Portfolios

Panel A: July 1963 to December 2000

\begin{tabular}{lcccccc}
\hline & Low IVOL & 2 & 3 & 4 & High IVOL & H - L \\
\hline \% Market Share & 36.93 & 26.05 & 18.71 & 13.01 & 5.35 & \\
Average Return & 1.078 & 1.068 & 1.032 & 1.277 & 1.052 & -0.026 \\
& $(5.37)$ & $(5.23)$ & $(4.86)$ & $(5.35)$ & $(3.82)$ & $(-0.14)$ \\
CAPM Alpha & 0.106 & 0.046 & -0.001 & 0.235 & -0.004 & -0.110 \\
& $(1.33)$ & $(0.60)$ & $(-0.01)$ & $(2.09)$ & $(-0.02)$ & $(-0.60)$ \\
FF3 Alpha & 0.030 & 0.006 & -0.021 & 0.190 & -0.071 & -0.101 \\
& $(0.43)$ & $(0.08)$ & $(-0.29)$ & $(1.69)$ & $(-0.34)$ & $(-0.52)$ \\
FF4 Alpha & 0.086 & 0.012 & 0.026 & 0.271 & 0.095 & 0.008 \\
& $(1.22)$ & $(0.15)$ & $(0.33)$ & $(2.22)$ & $(0.48)$ & $(0.04)$ \\
\hline
\end{tabular}

Panel B: November 1926 to June 2013

\begin{tabular}{lcccccc}
\hline & Low IVOL & 2 & 3 & 4 & High IVOL & H - L \\
\hline \% Market Share & 43.83 & 25.45 & 16.22 & 10.33 & 4.55 & \\
Average Return & 0.941 & 0.940 & 0.977 & 1.254 & 0.990 & 0.049 \\
& $(6.19)$ & $(5.55)$ & $(5.35)$ & $(6.51)$ & $(4.32)$ & $(0.35)$ \\
CAPM Alpha & 0.145 & 0.073 & 0.070 & 0.298 & 0.002 & -0.143 \\
& $(2.96)$ & $(1.22)$ & $(1.13)$ & $(3.65)$ & $(0.02)$ & $(-1.14)$ \\
FF3 Alpha & 0.172 & 0.081 & 0.076 & 0.259 & -0.056 & $-0.228^{*}$ \\
& $(3.58)$ & $(1.40)$ & $(1.24)$ & $(3.18)$ & $(-0.49)$ & $(-1.92)$ \\
FF4 Alpha & 0.166 & 0.049 & 0.083 & 0.307 & -0.063 & $-0.230^{*}$ \\
& $(3.24)$ & $(0.82)$ & $(1.29)$ & $(3.44)$ & $(-0.55)$ & $(-1.87)$ \\
\hline
\end{tabular}

Using the value weighted monthly returns of 49 industry portfolios, value weighted quintile portfolios are formed every month by sorting the 49 portfolios based on lagged idiosyncratic volatility measured relative to the Fama and French (1993) model using daily data. For each quintile portfolio, the table reports the time-series value weighted average return, CAPM alpha, Fama and French (1993) three factor alpha, and Carhart (1997) four factor alpha on a monthly basis in percentage points. The column labeled "H - L" reports the average return and alphas for a strategy that is long the portfolio of assets with the highest idiosyncratic volatility in the previous month and short the portfolio of assets with the lowest idiosyncratic volatility in the previous month. Newey and West (1987) heteroskedasticity-autocorrelation robust tstatistics are reported in parentheses with six months lag. $10 \%(*), 5 \%(* *)$, and $1 \%(* * *)$ significance levels are denoted for the "H - L" portfolio. 


\section{Table A9: Fama-MacBeth Regressions: 49 Industry Portfolios}

\begin{tabular}{|c|c|c|c|c|c|c|}
\hline & \multicolumn{3}{|c|}{ Panel A: July 1963 to December 2000} & \multicolumn{3}{|c|}{ Panel B: November 1926 to June 2013} \\
\hline & $1 \mathrm{~A}$ & $2 \mathrm{~A}$ & $3 \mathrm{~A}$ & $1 \mathrm{~B}$ & $2 \mathrm{~B}$ & $3 \mathrm{~B}$ \\
\hline \multirow[t]{2}{*}{ IVOL } & -0.253 & -0.230 & -0.230 & -0.084 & -0.132 & $-0.183^{* *}$ \\
\hline & $(-1.46)$ & $(-1.64)$ & $(-1.64)$ & $(-0.78)$ & $(-1.41)$ & $(-2.10)$ \\
\hline \multirow[t]{2}{*}{ Return(-1) } & & $0.045^{* * *}$ & $0.054^{* * *}$ & & $0.019^{*}$ & $0.024^{* *}$ \\
\hline & & $(3.51)$ & $(4.59)$ & & $(1.96)$ & $(2.49)$ \\
\hline \multirow[t]{2}{*}{$\operatorname{Return}(-7,-2)$} & & $0.016^{* * *}$ & $0.015^{* * *}$ & & $0.015^{* * *}$ & $0.015^{* * *}$ \\
\hline & & $(3.01)$ & $(2.88)$ & & $(3.67)$ & $(3.86)$ \\
\hline \multirow[t]{2}{*}{$\ln (\mathrm{SIZE})$} & & -0.012 & -0.033 & & -0.070 & -0.071 \\
\hline & & $(-0.18)$ & $(-0.47)$ & & $(-1.63)$ & $(-1.64)$ \\
\hline \multirow[t]{2}{*}{$\ln (\mathrm{B} / \mathrm{M})$} & & -0.001 & -0.015 & & 0.026 & 0.042 \\
\hline & & $(-0.02)$ & $(-0.26)$ & & $(0.55)$ & $(0.92)$ \\
\hline \multirow[t]{2}{*}{$\beta_{M K T}$} & & & 0.110 & & & -0.025 \\
\hline & & & $(0.84)$ & & & $(-0.19)$ \\
\hline \multirow[t]{2}{*}{$\beta_{S M B}$} & & & -0.122 & & & -0.089 \\
\hline & & & $(-1.58)$ & & & $(-1.55)$ \\
\hline \multirow[t]{2}{*}{$\beta_{H M L}$} & & & -0.037 & & & 0.026 \\
\hline & & & $(-0.50)$ & & & $(0.37)$ \\
\hline \multirow[t]{2}{*}{$\beta_{U M D}$} & & & 0.026 & & & 0.123 \\
\hline & & & $(0.30)$ & & & $(1.49)$ \\
\hline \multirow[t]{2}{*}{ Constant } & $0.730^{* * *}$ & 0.614 & 0.718 & $0.759^{* * *}$ & $0.851^{* *}$ & $0.991^{* * *}$ \\
\hline & $(3.23)$ & $(1.15)$ & (1.38) & $(4.48)$ & $(2.49)$ & $(3.20)$ \\
\hline $\operatorname{Adj} R^{2}$ & 0.060 & 0.190 & 0.278 & 0.061 & 0.172 & 0.261 \\
\hline
\end{tabular}

The table reports results from two-stage Fama and MacBeth (1973) regressions for 49 industry portfolios. Timeseries averages of estimated coefficients from monthly cross-sectional regressions are presented. The dependent variable is the value weighted monthly portfolio return minus the monthly risk-free rate (one-month Treasury bill rate) in month $t$. "IVOL" is the standard deviation of residuals from a regression of daily excess returns in month $t-1$ on the Fama and French (1993) model. "Return(-1)" is the value weighted monthly portfolio return in month $t-1$. "Return $(-7,-2)$ " is the buy-and-hold month $t-7$ to $t-2$ return. " $\ln (\mathrm{SIZE})$ " is the natural log of the average firm size in the portfolio in month $t-1$. " $\ln (\mathrm{B} / \mathrm{M})$ " is the natural log of the value weighted book-to-market ratio of the portfolio in month $t-1$. " $\beta_{M K T}$," " $\beta_{S M B}$," " $\beta_{H M L}$," and " $\beta_{U M D}$ " are the loadings in month $t-1$ on the market, size, book-to-market, and momentum risk factors of the Carhart (1997) four factor model estimated every month using daily data. The average adjusted $R^{2}$ of the cross-sectional regressions is reported. The sample period is July 1963 to December 2000 for Panel A and November 1926 to June 2013 for Panel B. Newey and West (1987) heteroskedasticity-autocorrelation robust t-statistics are reported in parentheses with six months lag. $10 \%(*), 5 \%(* *)$, and $1 \%(* * *)$ significance levels are denoted. 


\section{Table A10: Sorting of Exchange Traded Funds}

Panel A: All ETFs on CRSP

\begin{tabular}{lcccccc}
\hline & Low IVOL & 2 & 3 & 4 & High IVOL & H - L \\
\hline \% Market Share & 47.21 & 15.85 & 15.75 & 12.07 & 9.13 & \\
Average Return & 0.341 & 0.315 & 0.252 & 0.028 & 0.114 & -0.227 \\
& $(0.89)$ & $(0.79)$ & $(0.49)$ & $(0.04)$ & $(0.18)$ & $(-0.54)$ \\
CAPM Alpha & -0.061 & -0.093 & -0.210 & -0.461 & -0.369 & -0.308 \\
& $(-1.52)$ & $(-0.86)$ & $(-0.87)$ & $(-1.43)$ & $(-0.83)$ & $(-0.71)$ \\
FF3 Alpha & -0.067 & -0.101 & -0.038 & -0.244 & -0.103 & -0.036 \\
& $(-1.54)$ & $(-0.99)$ & $(-0.17)$ & $(-0.89)$ & $(-0.30)$ & $(-0.11)$ \\
FF4 Alpha & -0.062 & -0.095 & -0.038 & -0.225 & -0.088 & -0.026 \\
& $(-1.41)$ & $(-0.92)$ & $(-0.17)$ & $(-0.83)$ & $(-0.26)$ & $(-0.08)$ \\
\hline
\end{tabular}

Panel B: US Domestic Equity ETFs

\begin{tabular}{lcccccc}
\hline & Low IVOL & 2 & 3 & 4 & High IVOL & H - L \\
\hline \% Market Share & 61.10 & 15.93 & 8.65 & 7.28 & 7.03 & \\
Average Return & 0.419 & 0.587 & 0.388 & -0.160 & 0.316 & -0.104 \\
& $(0.95)$ & $(1.36)$ & $(0.88)$ & $(-0.23)$ & $(0.47)$ & $(-0.27)$ \\
CAPM Alpha & -0.020 & 0.140 & -0.065 & -0.678 & -0.241 & -0.221 \\
& $(-0.63)$ & $(1.27)$ & $(-0.43)$ & $(-2.18)$ & $(-0.64)$ & $(-0.57)$ \\
FF3 Alpha & -0.041 & 0.015 & -0.039 & -0.467 & -0.056 & -0.015 \\
& $(-1.98)$ & $(0.23)$ & $(-0.33)$ & $(-1.98)$ & $(-0.19)$ & $(-0.05)$ \\
FF4 Alpha & -0.037 & 0.009 & -0.036 & -0.457 & -0.018 & 0.019 \\
& $(-1.81)$ & $(0.13)$ & $(-0.29)$ & $(-1.90)$ & $(-0.06)$ & $(0.06)$ \\
\hline
\end{tabular}

Using the value weighted monthly returns of two samples of exchange traded funds, value weighted quintile portfolios are formed every month by sorting the ETFs based on lagged idiosyncratic volatility measured relative to the Fama and French (1993) model using daily data. For each quintile portfolio, the table reports the time-series value weighted average return, CAPM alpha, Fama and French (1993) three factor alpha, and Carhart (1997) four factor alpha on a monthly basis in percentage points. The column labeled " $\mathrm{H}$ - L" reports the average return and alphas for a strategy that is long the portfolio of assets with the highest idiosyncratic volatility in the previous month and short the portfolio of assets with the lowest idiosyncratic volatility in the previous month. Newey and West (1987) heteroskedasticityautocorrelation robust t-statistics are reported in parentheses with six months lag. $10 \%(*), 5 \%(* *)$, and $1 \%(* * *)$ significance levels are denoted for the "H - L" portfolio. 


\section{Table A11: Fama-MacBeth Regressions: Exchange Traded Funds}

\begin{tabular}{|c|c|c|c|c|c|c|}
\hline & \multicolumn{3}{|c|}{ Panel A: All ETFs on CRSP } & \multicolumn{3}{|c|}{ Panel B: US Domestic Equity ETFs } \\
\hline & $1 \mathrm{~A}$ & $2 \mathrm{~A}$ & $3 \mathrm{~A}$ & 1B & $2 \mathrm{~B}$ & 3B \\
\hline \multirow[t]{2}{*}{ IVOL } & 0.032 & -0.001 & 0.101 & -0.109 & -0.142 & -0.018 \\
\hline & $(0.14)$ & $(-0.01)$ & $(0.66)$ & $(-0.44)$ & $(-0.72)$ & $(-0.12)$ \\
\hline \multirow[t]{2}{*}{ Return(-1) } & & 0.039 & 0.028 & & 0.020 & 0.005 \\
\hline & & $(1.54)$ & $(1.43)$ & & $(0.82)$ & $(0.22)$ \\
\hline \multirow[t]{2}{*}{ Return $(-7,-2)$} & & 0.017 & $0.014^{*}$ & & 0.008 & 0.006 \\
\hline & & $(1.34)$ & $(1.93)$ & & $(0.69)$ & $(0.67)$ \\
\hline \multirow{2}{*}{$\ln$ (Market Cap) } & & $-0.027^{*}$ & -0.017 & & $-0.022^{*}$ & -0.001 \\
\hline & & $(-1.78)$ & $(-1.15)$ & & $(-1.78)$ & $(-0.04)$ \\
\hline \multirow[t]{2}{*}{$\beta_{M K T}$} & & & 0.085 & & & -0.192 \\
\hline & & & $(0.25)$ & & & $(-0.68)$ \\
\hline \multirow{2}{*}{$\beta_{S M B}$} & & & 0.092 & & & 0.067 \\
\hline & & & $(0.83)$ & & & $(0.58)$ \\
\hline \multirow[t]{2}{*}{$\beta_{H M L}$} & & & $0.186^{*}$ & & & 0.152 \\
\hline & & & $(1.70)$ & & & $(1.36)$ \\
\hline \multirow[t]{2}{*}{$\beta_{U M D}$} & & & -0.011 & & & 0.081 \\
\hline & & & $(-0.05)$ & & & $(0.37)$ \\
\hline \multirow[t]{2}{*}{ Constant } & 0.374 & 0.381 & 0.266 & 0.537 & 0.452 & 0.306 \\
\hline & $(1.07)$ & (1.16) & $(0.88)$ & $(1.28)$ & $(0.95)$ & $(0.70)$ \\
\hline $\operatorname{Adj} R^{2}$ & 0.046 & 0.291 & 0.463 & 0.071 & 0.233 & 0.402 \\
\hline
\end{tabular}

The table reports results from two-stage Fama and MacBeth (1973) regressions for two samples of exchange traded funds. Time-series averages of estimated coefficients from monthly cross-sectional regressions are presented. The dependent variable is the monthly portfolio return minus the monthly risk-free rate (one-month Treasury bill rate) in month $t$. "IVOL" is the standard deviation of residuals from a regression of daily excess returns in month $t-1$ on the Fama and French (1993) model. "Return(-1)" is the monthly portfolio return in month $t-1$. "Return $(-7,-2)$ " is the buy-and-hold month $t-7$ to $t-2$ return. "ln(Market Cap)" is the natural log of the market capitalization of the fund in month $t-1$. " $\beta_{M K T}$," " $\beta_{S M B}$," " $\beta_{H M L}$, " and " $\beta_{U M D}$ " are the loadings in month $t-1$ on the market, size, book-to-market, and momentum risk factors of the Carhart (1997) four factor model estimated every month using daily data. The average adjusted $R^{2}$ of the cross-sectional regressions is reported. The sample period is August 2000 to December 2013. Newey and West (1987) heteroskedasticity-autocorrelation robust t-statistics are reported in parentheses with six months lag. $10 \%(*), 5 \%(* *)$, and $1 \%(* * *)$ significance levels are denoted. 


\section{Table A12: Sorting of 100 Portfolios Formed on Size and B/M (Equal Weighted Returns)}

Panel A: July 1963 to December 2000

\begin{tabular}{lcccccc}
\hline & Low IVOL & 2 & 3 & 4 & High IVOL & H - L \\
\hline \% Market Share & 45.08 & 20.11 & 14.45 & 11.45 & 8.92 & \\
Average Return & 1.091 & 1.106 & 1.141 & 1.191 & 1.173 & 0.082 \\
& $(5.384)$ & $(5.357)$ & $(5.175)$ & $(5.076)$ & $(4.788)$ & $(0.529)$ \\
CAPM Alpha & 0.081 & 0.079 & 0.115 & 0.145 & 0.133 & 0.051 \\
& $(1.269)$ & $(1.098)$ & $(1.363)$ & $(1.406)$ & $(0.911)$ & $(0.334)$ \\
FF3 Alpha & 0.044 & -0.081 & -0.058 & -0.111 & -0.200 & $-0.244^{*}$ \\
& $(0.884)$ & $(-1.411)$ & $(-0.864)$ & $(-1.445)$ & $(-1.701)$ & $(-1.960)$ \\
FF4 Alpha & 0.131 & 0.034 & 0.031 & 0.003 & -0.044 & -0.175 \\
& $(2.101)$ & $(0.546)$ & $(0.459)$ & $(0.038)$ & $(-0.355)$ & $(-1.387)$ \\
\hline
\end{tabular}

Panel B: November 1926 to June 2013

\begin{tabular}{lcccccc}
\hline & Low IVOL & 2 & 3 & 4 & High IVOL & H - L \\
\hline \% Market Share & 57.31 & 17.04 & 11.39 & 8.49 & 5.89 & \\
Average Return & 0.965 & 1.053 & 1.131 & 1.084 & 1.257 & $0.292^{*}$ \\
& $(5.655)$ & $(5.045)$ & $(4.626)$ & $(4.743)$ & $(4.545)$ & $(1.912)$ \\
CAPM Alpha & 0.059 & 0.043 & 0.047 & 0.023 & 0.113 & 0.054 \\
& $(1.620)$ & $(0.673)$ & $(0.564)$ & $(0.245)$ & $(0.913)$ & $(0.431)$ \\
FF3 Alpha & 0.053 & -0.071 & -0.140 & -0.160 & -0.146 & $-0.199^{* *}$ \\
& $(1.595)$ & $(-1.521)$ & $(-2.323)$ & $(-2.353)$ & $(-1.541)$ & $(-2.134)$ \\
FF4 Alpha & 0.101 & -0.015 & 0.025 & -0.079 & -0.007 & -0.108 \\
& $(2.921)$ & $(-0.313)$ & $(0.364)$ & $(-1.146)$ & $(-0.076)$ & $(-1.137)$ \\
\hline
\end{tabular}

Using the equal weighted monthly returns of 100 portfolios formed on size and book-to-market, value weighted quintile portfolios are formed every month by sorting the 100 portfolios based on lagged idiosyncratic volatility measured relative to the Fama and French (1993) model using daily data. For each quintile portfolio, the table reports the time-series value weighted average return, CAPM alpha, Fama and French (1993) three factor alpha, and Carhart (1997) four factor alpha on a monthly basis in percentage points. The column labeled "H - L" reports the average return and alphas for a strategy that is long the portfolio of assets with the highest idiosyncratic volatility in the previous month and short the portfolio of assets with the lowest idiosyncratic volatility in the previous month. Newey and West (1987) heteroskedasticity-autocorrelation robust t-statistics are reported in parentheses with six months lag. $10 \%(*), 5 \%(* *)$, and $1 \%(* * *)$ significance levels are denoted for the "H - L" portfolio. 


\section{Table A13: Sorting of 25 Portfolios Formed on Size and B/M (Equal Weighted Returns)}

Panel A: July 1963 to December 2000

\begin{tabular}{lcccccc}
\hline & Low IVOL & 2 & 3 & 4 & High IVOL & H - L \\
\hline \% Market Share & 40.04 & 21.52 & 16.88 & 12.62 & 8.93 & \\
Average Return & 1.057 & 1.214 & 1.199 & 1.180 & 1.374 & $0.318^{* *}$ \\
& $(4.954)$ & $(5.430)$ & $(5.123)$ & $(4.891)$ & $(5.466)$ & $(2.271)$ \\
CAPM Alpha & 0.025 & 0.181 & 0.145 & 0.130 & 0.314 & $0.289^{* *}$ \\
& $(0.378)$ & $(1.991)$ & $(1.487)$ & $(1.203)$ & $(2.251)$ & $(2.064)$ \\
FF3 Alpha & -0.030 & 0.030 & -0.058 & -0.108 & 0.022 & 0.052 \\
& $(-0.424)$ & $(0.365)$ & $(-0.675)$ & $(-1.280)$ & $(0.212)$ & $(0.438)$ \\
FF4 Alpha & 0.037 & 0.108 & 0.095 & 0.081 & 0.174 & 0.136 \\
& $(0.477)$ & $(1.236)$ & $(1.139)$ & $(0.854)$ & $(1.594)$ & $(1.140)$ \\
\hline
\end{tabular}

Panel B: November 1926 to June 2013

\begin{tabular}{lcccccc}
\hline & Low IVOL & 2 & 3 & 4 & High IVOL & H - L \\
\hline \% Market Share & 53.85 & 18.59 & 12.57 & 9.04 & 5.96 & \\
Average Return & 0.982 & 1.111 & 1.140 & 1.193 & 1.340 & $0.358^{* *}$ \\
& $(5.444)$ & $(5.381)$ & $(4.712)$ & $(4.721)$ & $(5.080)$ & $(2.545)$ \\
CAPM Alpha & 0.047 & 0.118 & 0.058 & 0.058 & 0.206 & 0.159 \\
& $(1.097)$ & $(1.901)$ & $(0.696)$ & $(0.625)$ & $(1.621)$ & $(1.263)$ \\
FF3 Alpha & 0.029 & 0.013 & -0.131 & -0.175 & -0.036 & -0.065 \\
& $(0.724)$ & $(0.272)$ & $(-2.021)$ & $(-2.692)$ & $(-0.387)$ & $(-0.673)$ \\
FF4 Alpha & 0.081 & 0.081 & -0.019 & 0.025 & 0.126 & 0.046 \\
& $(1.950)$ & $(1.726)$ & $(-0.292)$ & $(0.333)$ & $(1.094)$ & $(0.397)$ \\
\hline
\end{tabular}

Using the equal weighted monthly returns of 25 portfolios formed on size and book-to-market, value weighted quintile portfolios are formed every month by sorting the 25 portfolios based on lagged idiosyncratic volatility measured relative to the Fama and French (1993) model using daily data. For each quintile portfolio, the table reports the time-series value weighted average return, CAPM alpha, Fama and French (1993) three factor alpha, and Carhart (1997) four factor alpha on a monthly basis in percentage points. The column labeled "H - L" reports the average return and alphas for a strategy that is long the portfolio of assets with the highest idiosyncratic volatility in the previous month and short the portfolio of assets with the lowest idiosyncratic volatility in the previous month. Newey and West (1987) heteroskedasticity-autocorrelation robust t-statistics are reported in parentheses with six months lag. $10 \%(*), 5 \%(* *)$, and $1 \%(* * *)$ significance levels are denoted for the "H - L" portfolio. 


\section{Table A14: Sorting of 49 Industry Portfolios (Equal Weighted Returns)}

Panel A: July 1963 to December 2000

\begin{tabular}{lcccccc}
\hline & Low IVOL & 2 & 3 & 4 & High IVOL & H - L \\
\hline \% Market Share & 38.93 & 27.12 & 18.35 & 11.69 & 3.97 & \\
Average Return & 1.208 & 1.362 & 1.229 & 1.404 & 1.339 & 0.131 \\
& $(4.638)$ & $(4.521)$ & $(3.888)$ & $(4.490)$ & $(4.538)$ & $(0.832)$ \\
CAPM Alpha & 0.200 & 0.272 & 0.115 & 0.336 & 0.294 & 0.094 \\
& $(1.526)$ & $(1.633)$ & $(0.658)$ & $(1.868)$ & $(1.483)$ & $(0.590)$ \\
FF3 Alpha & -0.069 & 0.107 & -0.045 & 0.171 & 0.085 & 0.154 \\
& $(-0.785)$ & $(1.276)$ & $(-0.430)$ & $(1.459)$ & $(0.518)$ & $(0.954)$ \\
FF4 Alpha & 0.066 & 0.243 & 0.098 & 0.270 & 0.081 & 0.015 \\
& $(0.999)$ & $(2.434)$ & $(0.894)$ & $(2.340)$ & $(0.467)$ & $(0.087)$ \\
\hline
\end{tabular}

Panel B: November 1926 to June 2013

\begin{tabular}{lcccccc}
\hline & Low IVOL & 2 & 3 & 4 & High IVOL & H - L \\
\hline \% Market Share & 45.45 & 24.68 & 16.37 & 9.90 & 3.94 & \\
Average Return & 1.204 & 1.242 & 1.257 & 1.321 & 1.590 & $0.386^{*}$ \\
& $(5.977)$ & $(5.545)$ & $(5.408)$ & $(5.606)$ & $(5.045)$ & $(1.818)$ \\
CAPM Alpha & 0.272 & 0.252 & 0.246 & 0.323 & 0.442 & 0.170 \\
& $(3.494)$ & $(2.678)$ & $(2.333)$ & $(2.852)$ & $(2.663)$ & $(1.114)$ \\
FF3 Alpha & 0.172 & 0.160 & 0.161 & 0.188 & 0.152 & -0.020 \\
& $(2.889)$ & $(2.248)$ & $(2.094)$ & $(2.221)$ & $(1.141)$ & $(-0.143)$ \\
FF4 Alpha & 0.232 & 0.268 & 0.231 & 0.278 & 0.442 & 0.210 \\
& $(3.374)$ & $(3.646)$ & $(2.646)$ & $(2.961)$ & $(2.427)$ & $(1.063)$ \\
\hline
\end{tabular}

Using the equal weighted monthly returns of 49 industry portfolios, value weighted quintile portfolios are formed every month by sorting the 49 portfolios based on lagged idiosyncratic volatility measured relative to the Fama and French (1993) model using daily data. For each quintile portfolio, the table reports the time-series value weighted average return, CAPM alpha, Fama and French (1993) three factor alpha, and Carhart (1997) four factor alpha on a monthly basis in percentage points. The column labeled "H - L" reports the average return and alphas for a strategy that is long the portfolio of assets with the highest idiosyncratic volatility in the previous month and short the portfolio of assets with the lowest idiosyncratic volatility in the previous month. Newey and West (1987) heteroskedasticity-autocorrelation robust tstatistics are reported in parentheses with six months lag. 10\%(*), 5\%(**), and 1\%(***) significance levels are denoted for the "H - L" portfolio. 


\section{Table A15: Fama-MacBeth Regressions: 100 Portfolios Formed on Size and B/M (Equal Weighted Returns)}

\begin{tabular}{|c|c|c|c|c|c|c|}
\hline & \multicolumn{3}{|c|}{ Panel A: July 1963 to December 2000} & \multicolumn{3}{|c|}{ Panel B: November 1926 to June 2013} \\
\hline & $1 \mathrm{~A}$ & $2 \mathrm{~A}$ & $3 \mathrm{~A}$ & $1 \mathrm{~B}$ & $2 \mathrm{~B}$ & $3 \mathrm{~B}$ \\
\hline \multirow[t]{2}{*}{ IVOL } & 0.014 & -0.188 & $-0.245^{* *}$ & -0.038 & -0.141 & -0.123 \\
\hline & $(0.06)$ & $(-1.44)$ & $(-1.98)$ & $(-0.32)$ & $(-1.59)$ & $(-1.43)$ \\
\hline \multirow[t]{2}{*}{$\operatorname{Return}(-1)$} & & -0.009 & -0.006 & & $-0.043^{* * *}$ & $-0.035^{* * *}$ \\
\hline & & $(-1.01)$ & $(-0.72)$ & & $(-5.68)$ & $(-4.90)$ \\
\hline \multirow[t]{2}{*}{$\operatorname{Return}(-7,-2)$} & & $0.009^{* *}$ & $0.008^{* *}$ & & 0.005 & 0.004 \\
\hline & & $(2.33)$ & $(2.23)$ & & $(1.61)$ & $(1.58)$ \\
\hline \multirow[t]{2}{*}{$\ln (\mathrm{SIZE})$} & & -0.037 & -0.042 & & $-0.090^{* *}$ & $-0.084^{* *}$ \\
\hline & & $(-0.80)$ & $(-0.80)$ & & $(-2.52)$ & $(-2.23)$ \\
\hline \multirow[t]{2}{*}{$\ln (\mathrm{B} / \mathrm{M})$} & & $0.250^{* *}$ & $0.275^{* * *}$ & & $0.237^{* * *}$ & $0.244^{* * *}$ \\
\hline & & $(2.50)$ & $(3.02)$ & & $(3.38)$ & $(3.79)$ \\
\hline \multirow{2}{*}{$\beta_{M K T}$} & & & 0.073 & & & -0.027 \\
\hline & & & $(0.63)$ & & & $(-0.32)$ \\
\hline \multirow[t]{2}{*}{$\beta_{S M B}$} & & & -0.007 & & & 0.004 \\
\hline & & & $(-0.11)$ & & & $(0.09)$ \\
\hline \multirow[t]{2}{*}{$\beta_{H M L}$} & & & -0.065 & & & $-0.084^{*}$ \\
\hline & & & $(-1.23)$ & & & $(-1.87)$ \\
\hline \multirow[t]{2}{*}{$\beta_{U M D}$} & & & 0.053 & & & $0.090^{*}$ \\
\hline & & & $(0.79)$ & & & $(1.68)$ \\
\hline \multirow[t]{2}{*}{ Constant } & $0.721^{* * *}$ & $0.956^{* *}$ & $1.024^{* *}$ & $0.907^{* * *}$ & $1.202^{* * *}$ & $1.206^{* * *}$ \\
\hline & $(2.87)$ & $(2.30)$ & $(2.47)$ & $(4.37)$ & $(3.96)$ & $(4.13)$ \\
\hline $\operatorname{Adj} R^{2}$ & 0.029 & 0.315 & 0.350 & 0.056 & 0.270 & 0.325 \\
\hline
\end{tabular}

The table reports results from two-stage Fama and MacBeth (1973) regressions for 100 portfolios formed on size and book-to-market. Time-series averages of estimated coefficients from monthly cross-sectional regressions are presented. The dependent variable is the equal weighted monthly portfolio return minus the monthly risk-free rate (one-month Treasury bill rate) in month $t$. "IVOL" is the standard deviation of residuals from a regression of daily excess returns in month $t-1$ on the Fama and French (1993) model. "Return(-1)" is the equal weighted monthly portfolio return in month $t-1$. "Return(-7,-2)" is the buy-and-hold month $t-7$ to $t-2$ return. "ln(SIZE)" is the natural $\log$ of the average firm size in the portfolio in month $t-1$. " $\ln (\mathrm{B} / \mathrm{M})$ " is the natural log of the ratio of the sum of book equity to the sum of market equity in month $t-1$. " $\beta_{M K T}$," " $\beta_{S M B}$," " $\beta_{H M L}$," and " $\beta_{U M D}$ " are the loadings in month $t-1$ on the market, size, book-to-market, and momentum risk factors of the Carhart (1997) four factor model estimated every month using daily data. The average adjusted $R^{2}$ of the cross-sectional regressions is reported. The sample period is July 1963 to December 2000 for Panel A and November 1926 to June 2013 for Panel B. Newey and West (1987) heteroskedasticity-autocorrelation robust t-statistics are reported in parentheses with six months lag. $10 \%(*), 5 \%(* *)$, and $1 \%(* * *)$ significance levels are denoted. 


\section{Table A16: Fama-MacBeth Regressions: 25 Portfolios Formed on Size and B/M (Equal Weighted Returns)}

\begin{tabular}{|c|c|c|c|c|c|c|}
\hline & \multicolumn{3}{|c|}{ Panel A: July 1963 to December 2000} & \multicolumn{3}{|c|}{ Panel B: November 1926 to June 2013} \\
\hline & $1 \mathrm{~A}$ & $2 \mathrm{~A}$ & $3 \mathrm{~A}$ & $1 \mathrm{~B}$ & $2 \mathrm{~B}$ & $3 \mathrm{~B}$ \\
\hline \multirow[t]{2}{*}{ IVOL } & 0.017 & -0.320 & -0.186 & -0.117 & -0.292 & -0.092 \\
\hline & $(0.03)$ & $(-0.92)$ & $(-0.50)$ & $(-0.36)$ & $(-1.42)$ & $(-0.43)$ \\
\hline \multirow[t]{2}{*}{$\operatorname{Return}(-1)$} & & 0.025 & $0.027^{*}$ & & $-0.022^{* *}$ & -0.006 \\
\hline & & $(1.57)$ & $(1.66)$ & & $(-2.03)$ & $(-0.50)$ \\
\hline \multirow[t]{2}{*}{$\operatorname{Return}(-7,-2)$} & & $0.011^{*}$ & $0.013^{*}$ & & $0.010^{* *}$ & $0.011^{* *}$ \\
\hline & & $(1.66)$ & $(1.93)$ & & $(2.07)$ & $(2.51)$ \\
\hline \multirow[t]{2}{*}{$\ln (\mathrm{SIZE})$} & & -0.043 & -0.034 & & $-0.069^{* *}$ & -0.044 \\
\hline & & $(-1.00)$ & $(-0.60)$ & & $(-2.11)$ & $(-1.18)$ \\
\hline \multirow[t]{2}{*}{$\ln (\mathrm{B} / \mathrm{M})$} & & $0.219^{* *}$ & $0.324^{* * *}$ & & $0.265^{* * *}$ & $0.295^{* * *}$ \\
\hline & & $(2.03)$ & $(3.05)$ & & $(3.35)$ & $(4.11)$ \\
\hline \multirow[t]{2}{*}{$\beta_{M K T}$} & & & -0.084 & & & $-0.284^{* *}$ \\
\hline & & & $(-0.49)$ & & & $(-2.21)$ \\
\hline \multirow[t]{2}{*}{$\beta_{S M B}$} & & & 0.028 & & & 0.056 \\
\hline & & & $(0.21)$ & & & $(0.64)$ \\
\hline \multirow[t]{2}{*}{$\beta_{H M L}$} & & & $-0.203^{* *}$ & & & $-0.199^{* *}$ \\
\hline & & & $(-2.27)$ & & & $(-2.48)$ \\
\hline \multirow[t]{2}{*}{$\beta_{U M D}$} & & & -0.053 & & & 0.114 \\
\hline & & & $(-0.53)$ & & & $(1.27)$ \\
\hline \multirow[t]{2}{*}{ Constant } & $0.717^{* * *}$ & $0.925^{* *}$ & $1.060^{* *}$ & $0.928^{* * *}$ & $1.074^{* * *}$ & $1.178^{* * *}$ \\
\hline & $(2.83)$ & $(2.18)$ & $(2.41)$ & $(4.47)$ & $(3.66)$ & $(4.01)$ \\
\hline $\operatorname{Adj} R^{2}$ & 0.063 & 0.539 & 0.590 & 0.111 & 0.482 & 0.559 \\
\hline
\end{tabular}

The table reports results from two-stage Fama and MacBeth (1973) regressions for 25 portfolios formed on size and book-to-market. Time-series averages of estimated coefficients from monthly cross-sectional regressions are presented. The dependent variable is the equal weighted monthly portfolio return minus the monthly risk-free rate (one-month Treasury bill rate) in month $t$. "IVOL" is the standard deviation of residuals from a regression of daily excess returns in month $t-1$ on the Fama and French (1993) model. "Return(-1)" is the equal weighted monthly portfolio return in month $t-1$. "Return(-7,-2)" is the buy-and-hold month $t-7$ to $t-2$ return. "ln(SIZE)" is the natural $\log$ of the average firm size in the portfolio in month $t-1$. " $\ln (\mathrm{B} / \mathrm{M})$ " is the natural log of the ratio of the sum of book equity to the sum of market equity in month $t-1$. " $\beta_{M K T}$," " $\beta_{S M B}$," " $\beta_{H M L}$," and " $\beta_{U M D}$ " are the loadings in month $t-1$ on the market, size, book-to-market, and momentum risk factors of the Carhart (1997) four factor model estimated every month using daily data. The average adjusted $R^{2}$ of the cross-sectional regressions is reported. The sample period is July 1963 to December 2000 for Panel A and November 1926 to June 2013 for Panel B. Newey and West (1987) heteroskedasticity-autocorrelation robust t-statistics are reported in parentheses with six months lag. $10 \%(*), 5 \%(* *)$, and $1 \%(* * *)$ significance levels are denoted. 


\section{Table A17: Fama-MacBeth Regressions: 49 Industry Portfolios (Equal Weighted Returns)}

\begin{tabular}{|c|c|c|c|c|c|c|}
\hline & \multicolumn{3}{|c|}{ Panel A: July 1963 to December 2000} & \multicolumn{3}{|c|}{ Panel B: November 1926 to June 2013} \\
\hline & $1 \mathrm{~A}$ & $2 \mathrm{~A}$ & $3 \mathrm{~A}$ & $1 \mathrm{~B}$ & $2 \mathrm{~B}$ & $3 \mathrm{~B}$ \\
\hline \multirow[t]{2}{*}{ IVOL } & -0.238 & -0.183 & -0.121 & -0.011 & -0.003 & 0.026 \\
\hline & $(-1.50)$ & $(-1.44)$ & $(-0.98)$ & $(-0.11)$ & $(-0.03)$ & $(0.31)$ \\
\hline \multirow[t]{2}{*}{ Return(-1) } & & $0.099^{* * *}$ & $0.107^{* * *}$ & & $0.048^{* * *}$ & $0.058^{* * *}$ \\
\hline & & $(6.70)$ & $(7.64)$ & & $(4.30)$ & $(5.46)$ \\
\hline \multirow[t]{2}{*}{$\operatorname{Return}(-7,-2)$} & & $0.030^{* * *}$ & $0.033^{* * *}$ & & $0.024^{* * *}$ & $0.025^{* * *}$ \\
\hline & & $(5.33)$ & $(6.36)$ & & $(5.87)$ & $(6.11)$ \\
\hline \multirow[t]{2}{*}{$\ln (\mathrm{SIZE})$} & & 0.009 & 0.018 & & 0.002 & 0.016 \\
\hline & & $(0.20)$ & $(0.36)$ & & $(0.04)$ & $(0.43)$ \\
\hline \multirow[t]{2}{*}{$\ln (\mathrm{B} / \mathrm{M})$} & & 0.021 & 0.012 & & 0.011 & 0.032 \\
\hline & & $(0.41)$ & $(0.24)$ & & $(0.22)$ & $(0.65)$ \\
\hline \multirow[t]{2}{*}{$\beta_{M K T}$} & & & 0.160 & & & -0.038 \\
\hline & & & $(0.84)$ & & & $(-0.30)$ \\
\hline \multirow[t]{2}{*}{$\beta_{S M B}$} & & & -0.128 & & & -0.045 \\
\hline & & & $(-1.04)$ & & & $(-0.63)$ \\
\hline \multirow[t]{2}{*}{$\beta_{H M L}$} & & & 0.064 & & & 0.041 \\
\hline & & & $(0.64)$ & & & $(0.57)$ \\
\hline \multirow[t]{2}{*}{$\beta_{U M D}$} & & & $-0.191^{*}$ & & & 0.020 \\
\hline & & & $(-1.69)$ & & & $(0.21)$ \\
\hline \multirow[t]{2}{*}{ Constant } & $0.839^{* * *}$ & 0.471 & 0.278 & $0.929^{* * *}$ & $0.691^{* *}$ & $0.596^{*}$ \\
\hline & $(2.77)$ & $(0.97)$ & $(0.60)$ & $(4.16)$ & $(1.99)$ & $(1.80)$ \\
\hline $\operatorname{Adj} R^{2}$ & 0.066 & 0.202 & 0.305 & 0.066 & 0.181 & 0.280 \\
\hline
\end{tabular}

The table reports results from two-stage Fama and MacBeth (1973) regressions for 49 industry portfolios. Timeseries averages of estimated coefficients from monthly cross-sectional regressions are presented. The dependent variable is the equal weighted monthly portfolio return minus the monthly risk-free rate (one-month Treasury bill rate) in month $t$. "IVOL" is the standard deviation of residuals from a regression of daily excess returns in month $t-1$ on the Fama and French (1993) model. "Return(-1)" is the equal weighted monthly portfolio return in month $t-1$. "Return(-7,-2)" is the buy-and-hold month $t-7$ to $t-2$ return. " $\ln (\mathrm{SIZE})$ " is the natural log of the average firm size in the portfolio in month $t-1$. " $\ln (\mathrm{B} / \mathrm{M})$ " is the natural $\log$ of the ratio of the sum of book equity to the sum of market equity in month $t-1$. " $\beta_{M K T}$," " $\beta_{S M B}$," " $\beta_{H M L}$," and " $\beta_{U M D}$ " are the loadings in month $t-1$ on the market, size, book-to-market, and momentum risk factors of the Carhart (1997) four factor model estimated every month using daily data. The average adjusted $R^{2}$ of the cross-sectional regressions is reported. The sample period is July 1963 to December 2000 for Panel A and November 1926 to June 2013 for Panel B. Newey and West (1987) heteroskedasticity-autocorrelation robust t-statistics are reported in parentheses with six months lag. $10 \%(*), 5 \%(* *)$, and $1 \%(* * *)$ significance levels are denoted. 